\author{
Economics Working Paper Series
}

2017/025

\title{
Dealer Networks in the World of Art
}

\author{
Dakshina G. De Silva, Marina Gertsberg, \\ Georgia Kosmopoulou and Rachel A. J. Pownall
}

The Department of Economics

Lancaster University Management School

Lancaster LA1 4YX

UK 


\title{
Dealer Networks in the World of Art*
}

\author{
Dakshina G. De Silva ${ }^{\dagger}$ \\ Marina Gertsberg ${ }^{\ddagger}$ \\ Georgia Kosmopoulou ${ }^{\S}$ \\ Rachel A. J. Pownall ${ }^{\top}$
}

October 9, 2017

\begin{abstract}
We apply network theory to study auction outcomes in the fine art market. Using a unique historical data set, of London-based art auctions that took place between 1741 and 1913, we investigate the drivers of strategic network formation between dealers (buyers) and sellers and the effect of network structure on artwork prices and market exit. The network size and similarities in art specialization between trading partners strongly influence the decision to form links. A larger network and a higher degree of specialization exacerbate informational asymmetries across buyers leading to higher rents through lower prices and facilitate longer market presence.
\end{abstract}

Keywords: Auctions, Art Dealers, Networks

JEL Codes: D44, D82, L14

\footnotetext{
${ }^{*}$ The authors would like to thank Francesco Decarolis, Sanjeev Goyal, Svitlana Gertsberg, the conference participants of EARIE, the Conference on Auctions, Competition, Regulation and Public Policy, and the Conference on Research on Economic Theory and Econometrics for valuable comments.

${ }^{\dagger}$ Lancaster University, Lancaster, LA1 4YX, The UK; Email: d.desilva@lancaster.ac.uk

${ }^{\ddagger}$ Maastricht University, P.O. Box 616, Maastricht, 6200 MD, The Netherlands; Email: m.gertsberg@ maastrichtuniversity.nl

${ }^{\S}$ University of Oklahoma, Norman OK, 73019, USA; Email: :georgiak@ou.edu

`Maastricht University, P.O. Box 616, Maastricht, 6200 MD, The Netherlands; Email: r.pownall@ maastrichtuniversity.nl
} 


\section{Introduction}

An agent's superior market performance is typically the result of privately held information. In addition to accumulated experience, the professional network that surrounds an agent can contribute to heterogeneity in proprietary knowledge (Bala and Goyal, 1998). The quantity and exclusivity of information delivered by a network ultimately depends on its topology and the relative position assumed by the agent. This paper employs network theory to investigate the drivers of network formation and the effect of network structure on bidding behavior within the context of fine art auctions. We analyze strategic link formation between buyers and sellers created through transactions at auction events. Our focus is on professional art dealers who mainly assume the role of buyers within this bipartite network structure. Through this analysis, we are interested in answering three questions. First, what drives link formation choices of art dealers? Second, how does a dealer's network affect the price of an artwork? Third, what is the influence of the network on the dealer's likelihood to sustain an active presence in auction markets?

We use a rare London-based fine art auction data set, with buyer and seller identities, spanning the period 1741 to 1913 . This data provides us with a unique opportunity to study a network evolving over a long period of time, from its beginning, when art dealers made initial choices, building connections that affected their payoffs at auctions. The most revealing result of the study is that the relative size of a dealer's network is shaping competitive outcomes. The number of direct links and similarities in product specialization between buyer and seller are both strong predictors of the formation of future links as well as the prices of artworks. Those links can produce advantages leading to the propagation of a dealer's success. In addition, we find that dealers are more likely to form links early on but are more reluctant to bid aggressively. Lastly, we find that dealers with a larger network are also less likely to exit the auction market.

It is well established that, in common value auctions with asymmetric information, the expected rent a bidder can extract depends on her level of information (Milgrom and Weber, 1982). However, the ability to gain non-zero profit is contingent on the exclusivity of information. If two bidders obtain the same publicly available signal about the value of a good, a third auction participant, who may have less accurate but private information, will extract higher rents than the other two bidders (Engelbrecht-Wiggans et al., 1983). Hence, the privacy as opposed to the accuracy of information is regarded as a key explanatory factor in the observed heterogeneity of profits among bidders at 
auction.

A network characterized by many linkages among agents and a high density can lead to more efficient information diffusion resulting in dissipation of profits as the quantity of privately held information is diminished (Colla and Mele, 2010; Ozsoylev and Walden, 2011). However, when agents are not well connected through linkages, information asymmetries arise. Agents who have a central position in these networks have preferential access to information as it reaches them easier and faster. For instance, in the finance literature, Ozsoylev et al. (2014) empirically show that the topology of a network influences information diffusion among equity investors at the Istanbul Stock Exchange which, in turn, influences their returns. Centrally located investors earn higher returns and trade earlier than peripheral investors upon the arrival of new information.

In addition to the size of the network, the quality of the established connections can impact the type of acquired information. While links with diverse agents may increase the variety of information, homogeneous relationships can increase the depth of information and yield other type-dependent benefits (McPherson et al., 2001). Moreover, the frequency of interaction can increase the quality of information and result in better trade conditions (Cocco et al., 2009; Karlan et al., 2009). Such a diversified and well-connected network increases the set of possibilities for exchange resulting in greater bargaining power for the agent (Corominas-Bosch, 2004). Consequently, the formation of links becomes an imperative strategic consideration for market participants as the resulting relative position in the network will influence the level of rents that can be extracted.

A number of studies in the economics and finance network literature focus on how different characteristics might affect link formation and result in preferential attachment. For instance, Lux (2015) provide a dynamic model of interbank credit relationships. The author demonstrates that while, at first, formations are random, preferential relationships develop over time due to a learning mechanism. ${ }^{1}$ Commonly studied factors that induce preferential attachment are, among others, demographic characteristics, trust, and performance indicators. Currarini et al. (2009) develop a model for friendship formation and show that, independent of group structure, there is a bias towards same-type relationships with respect to demographics. The theoretical paper of Iori et al. (2015) uses memory to proxy trust in the setting of intrabank lending. The authors show that, with repeated pairwise interaction between borrower and lender, it becomes more likely for the lender to prefer

\footnotetext{
${ }^{1}$ Preferential attachment is the tendency to condition random link formation on characteristics of the nodes, making it more likely to create links with certain agents than with others.
} 
a repeat borrower over other borrowers in the market. Cocco et al. (2009) empirically analyze the Portuguese short-term intrabank lending market. The authors provide evidence that small banks are more likely to replenish liquidity through loans from banks they have established a relationship with in the past resulting in better loan conditions from these banks. This indicates that evolving trust in established relationships can reduce information asymmetries. However, the authors focus on direct pairwise exchanges as opposed to the overall nexus of indirect relationships. Our analysis extends this literature by demonstrating how node- and link-specific characteristics affect the strategic behavior of market players within the context of a newly evolving network over the time span of a century and a half.

Few theoretical studies have explicitly investigated networks of sellers and buyers through bipartite graphs (Corominas-Bosch, 2004; Kranton and Minehart, 2000, 2001; Uzzi, 1996) and their focus has not been on network structures varying by the degree or strength of connection. We provide empirical evidence for the effect of a comprehensive number of such network measures on the probability of link formation and the bidding strategies of agents in a real-life auction network.

Our analysis is conducted in three parts. First, we investigate the determinants of link formation between buyers and sellers at auction using Bayesian methods. Bayesian analysis allows us to incorporate information on prior link formation choices in future decisions. This enables us to make statements about the likelihood of establishing a connection. We expect that the buyer will only form a link if she derives a positive utility from this connection.

In our model, the utility of a new connection depends on the size of the buyer's direct network and link-specific characteristics. The latter includes the number of times the buyer and seller have interacted with each other in the past, the number of common connections they share, and the similarity in terms of their respective product specializations (artistic genre) throughout their trading history. Based on the findings in the previous literature on strategic link formation (Jackson and Wolinsky, 1996; Goyal, 2012), we expect that the probability of link formation increases with a larger number of established links with distinct trading partners. These diverse links can provide an agent with knowledge, market experience and visibility raising her popularity as a trading partner. Further, we expect the probability of link formation to increase if the agents have interacted with each other or each other's former trading partners (common connections) in the past. Lastly, similarities in trading patterns and product specializations should reduce information asymmetries between the players and 
make a trade more likely to occur. This is consistent with the idea of preferential attachment.

In the second step of our study, we analyze the effect of a dealer's individual network on the price of the artwork at auction. We employ the posterior Bayesian estimates derived in the first step of the analysis to address endogeneity concerns by estimating the number of competitors. Our expectation is that the price of an artwork will depend on an agent's number of established links in the past. A larger network should provide diverse information on the overall market conditions leading to profit-enhancing decisions (Colla and Mele, 2010; Ozsoylev et al., 2014). Repeated transactions with the same seller reduce the cost of information acquisition with a potential price-cost passthrough. We also expect that, controlling for artwork, bidder, and rival characteristics, a relatively more specialized dealer should have access to proprietary information that can lead to higher profit margins manifested in lower prices.

In the last part of our analysis, we investigate how a dealer's position in the network affects her ability to maintain market presence. If a superior network indeed provides a dealer with better information and opportunities for trade leading to higher profit margins, we should expect that she will stay longer in the market. This is also commonly observed in the entrepreneurship literature, where findings show that start-ups with better informal and formal networks are more likely to survive in the market (Brüderl and Preisendörfer, 1998; Dubini and Aldrich, 1991; Hoang and Antoncic, 2003; Raz and Gloor, 2007).

Our results provide strong empirical evidence that the network structure plays an important role in the link formation decision, the price, and survival in the market. Dealers are more likely to form a new link if they have established a higher number of distinct connections in the past. Further, the probability of a link formation increases in proportion to the frequency of repeated interaction between the same pair of agents. Similarly, we find that, if trading partners share common connections, they are also more likely to initiate trade. Conditional on prior link formation, dealers who are less exposed to the auction market are more eager to purchase artworks. Lastly, our results show that a connection between two agents becomes more probable, the more similar the buyer and seller are in their trading patterns and specializations in terms of artistic genre. As a result, it appears that agents prefer to interact with trading partners who are highly active in the market, with whom a relationship has already been established, and who are alike in terms of product specialization. 
With respect to the effect of the dealer's network on price, we find that the number of distinct networks is the most important predictor of the dealer's winning bid. Having a higher number of direct connections to sellers and a limited number of connections to other dealers amplifies informational asymmetries thus increasing one's market power, leading to lower prices and higher returns (consistent with Engelbrecht-Wiggans et al. (1983)). Further, repeated interactions with the same seller have a decreasing effect on price as an established relationship may lower information barriers and create profitable opportunities. Higher specialization in a traded genre allows the dealer to acquire artworks at lower prices. A rival's size of network and market power raises the price for a winning bidder.

Finally, we show that a better connected dealer is less likely to refrain from market activity than a dealer who has established a lower number of direct links. Both the level of market exposure and market share exert a positive effect on a dealer's likelihood to stay active in the market. The number of competitors alone does not have a statistically significant impact on the likelihood of exit; what matters most is how connected these competitors are. Dealers with lower market exposure are eager to form links but are reluctant to bid aggressively.

Overall, these findings suggest that a dealer's position in a network is the key to market success as it facilitates information flow which, in turn, improves strategic link formation resulting in superior conditions of exchange. Our contribution is unique in the sense that bipartite network structures have not been investigated before in auction markets. Moreover, our rich data set enables us to observe and analyze the emergence of a network in a nascent market. We show that the link formation process in art auctions is not random, but dependent on the structure of the prevalent network and the competitive considerations of its participants, thus highlighting network paths that may lead to a dealer's success. While it is well established in the auction literature that agents with superior information can extract higher rents in auctions (Engelbrecht-Wiggans et al., 1983; Hendricks and Porter, 1988), we illustrate how an agent's network can constitute the source of superior information.

Our findings have important implications for large size networks with pairwise links, and a limited amount of central actors. Inequalities in the number of connections seem to be persistent and offer advantages to few players who are located in the center of the network. These types of network structures can create externalities for other directly connected network participants, yet limit the ripple effects of market shocks. Hence, identifying and closing connection gaps in the network 
structure could be beneficial not only to individuals but also to the entire network. ${ }^{2}$

The paper proceeds as follows. In Section 2, we present our model which guides predictions with respect to prices and link formation at auctions. The data set is described in Section 3. Section 4 is dedicated to the empirical analysis and details the methodology and results with respect to network formation, bidding implications and exit patterns. We finish with some concluding remarks and implications for the art market as well as similar network structures in general in Section 5 .

\section{Model}

In any time period $t, n$ individuals are active in the art market and are considering the possibility of engaging in transactions thus forming links. Links offer learning opportunities, allowing the formation of a network among market participants. There are $T$ periods in the network formation and individuals can engage in market transactions more than once via an auction. The value, $V_{i j, t}$, of artwork, $i$, offered to a prospective buyer $j$ at time $t$ is not observed directly at the time of the auction. The expected value of the artwork, and the decision on how much to bid by a bidder, $j$, depends on the characteristics of the artwork on sale, $X_{i}$, the state of the existing network, $N$ at $t-1$, and the information revealed through the auction process. The adjacency matrix, $\mathcal{N}_{t-1}$, provides information on the state of the network in period $t-1$, with $\mathcal{N}_{j k, t-1}=1$ for all $(j, k)$ that have formed links up until period $t-1$ and $\mathcal{N}_{j k, t-1}=0$ if no link has been formed up to this period. For bidder $j$, the network structure until time $t-1, N_{t-1}$, compiles information about all prior connections and allows a mapping of artwork characteristics to form value estimates in period $t$. In particular, the distribution of estimates $Z_{j i, t}=f_{j}\left(N_{t-1}, X_{i}\right)$ reflects the asymmetries across bidders through a varied network structure. The broader the network, the less noisy the signal received that is linked to the value of the artwork for sale. The artwork characteristics and network structure are common knowledge but the information filtering through the network is essential in determining the value estimates.

Expected price: The auction house uses an English auction format to sell to bidders. The auctioneer calls bids and the willing bidders indicate their desire to buy with a gesture. The auction

\footnotetext{
${ }^{2}$ Findings in network analysis in the domain of the financial industry indicate that the probability of systemic shocks is lower in complete (well-connected) networks as these can be absorbed by more agents. However, if shocks occur, they spread wider and quicker in complete networks, negatively affecting more agents compared to less connected networks (see Allen and Gale (2000); Babus (2016); Furfine (2003); Gai and Kapadia (2010); Lux (2015).
} 
ends when no one is willing to raise the price any further. The seller indexed by $l$ has a reputation $R_{l, t}$ which, in our application, will reflect his volume of past sales that is common knowledge across bidders. The auction format is the asymmetric analogue of the irrevocable dropout auction described in Milgrom and Weber (1982). The asymmetric version was first presented in Wilson (1998) and generalized in Hong and Shum (2003) (HS thereafter) to encompass the common and private value frameworks as in Milgrom and Weber (1982). Our indexing convention follows HS. In particular, there are $n-1$ rounds at auction indexed by $k=0, \ldots, n-2$. All $n$ bidders are active in round 0 and only 2 bidders are active in round $n-2$ determining the final price. Without loss of generality, the ordering $1, \ldots, n$ denotes the reverse order of dropouts, with bidder $n$ dropping out first in round 0 and bidder 2 dropping out in round $n-2$, allowing bidder 1 to win the auction. Considering the set of signals, $Z_{i}$ at time t, let $Z_{1 i, t}, Z_{2 i, t}, \ldots, Z_{n i, t}$ denote buyer estimates ranked from largest to smallest. The dropout prices are indexed by $p_{0, i, t}, \ldots, p_{n-2, i, t}$. At round $k, n-k$ bidders have dropped out and the last recorded offer is $p_{k, i, t}$. The assumptions made here are that: (A1) $E\left(V_{i j, t} \mid \mathrm{Z}_{1 i, t,}, \ldots, Z_{n i, t} ; R_{l, t}\right)$ is strictly increasing in $Z_{j i, t}$ for all $j=1, \ldots, n$ and, (A2) the bidding strategy is monotonic in $Z_{j i, t}$ for any individual $j$, and for any realization of dropout prices up to that point. A function $b_{j}^{k}$ utilizes all available information at round $k$ consisting of a list of dropout prices to allow bidder $j$ to make a bidding decision. Given the artwork's observed characteristics and the network structure, that are common knowledge across bidders, the expected price in the auction can be inferred directly by the bidding strategies in Proposition 1 of HS:

$$
p_{n-2}=E\left(V_{j i, t} \mid\left(b_{1}^{n-2}\right)^{-1}\left(b_{2}\left(Z_{2 i, t}\right)\right), Z_{2 i, t} ; \Omega_{n-2}\right)
$$

where $\Omega_{n-2}=\left\{Z_{l i, t}=\left(b_{l}^{n-l}\right)^{-1}\left(p_{n-l}\right), l=3, \ldots, n,\right\}$ is an information set consisting of signals inferred by inverting dropout prices at every stage and $p_{0, i, t} \leqq p_{2, i, t} \leqq \ldots \leqq p_{n-3, i, t}$ are dropout prices of the bidders with the lowest $n-2$ signals. Clearly, (A1) and (A2) imply that the equilibrium price increases in the value of a rival's signal. The introduction of a network into the model introduces the element of asymmetric information across bidders. Holding superior information relative to that of competitors could enhance relative profits. In the spirit of Engelbrecht-Wiggans et al. (1983) and Hendricks and Porter (1988), the most informed bidder who has superior information to everyone else enjoys higher profit margins. 
The impact of the network structure on the mapping of $X_{i}$ into $Z_{j i, t}$ is critical for the formation of prices. One of the most significant challenges in obtaining a closed form solution for the set of bidding strategies of an asymmetric auction is the fact that the updating process used to incorporate the information provided by the dropout prices requires a significant demand for recursive actions. HS presented an example of a parametric family of distributions for which the conditional expectation functions describing equilibrium bidding functions have closed form solutions. In this example, bidder valuations are log-normally distributed and, in a common value context, better information leads to higher information rents. In the context of our empirical framework, the broader the network is, the more informed the bidders are expected to be (relative to their competitors) leading to higher profit margins and higher likelihood of forming new links. A challenge in our empirical application is the lack of information on the losing bids within an auction that would provide direct signaling information on competitors. We proxy competitor signals by the past network size, maximum capacity and market share of all potential rivals in the same auction sale.

Link formation: Every period, the seller selects an auction house that will maximize her return and then the bidders decide on whether to buy her artwork advertised in the auction catalog. Christie's auction house had nearly or effectively a monopoly position in the trade of fine art during our period of analysis, capturing $97 \%$ of the market by number and by value of acquisitions. In that sense, the sellers' choices had almost no variation.

A bidder's decision to form a link depends on the expected utility from purchasing the artwork. Denoting the unconditional utility of buyer $j$ as $U_{j}(l)$, a link is formed if $E\left(U_{j}\left(l \mid D_{j, t}, R_{l, t}, N_{t-1}\right) \geq 0\right.$. The utility depends on the bidder's characteristics, $D_{j, t}$, the reputation of the seller, and the network structure which includes information on competitors. ${ }^{3}$ The parametric form introduced in section 4.1 will explore the nature of those connections focusing on the buyer's decision to connect to one specific seller among those who compete to sell their artwork. In our empirical section, we will assume that bidders form expectations about the structure of the network up until time $t-1$ following this framework and based on that expected network structure, they formulate their bidding strategies that determine the price at auction in period $t$.

\footnotetext{
${ }^{3}$ In a common value framework, the typical assumption in the literature is that the value of the artwork for the seller is lower than that of the buyers and, in the affiliated value context, participants have a private as well as a common value component that makes trading opportunities profitable. The number of artworks that were buy-ins in our sample is in fact limited to $5.6 \%$ of all transactions and we don't have any bid information on those auctions.
} 


\section{Data}

\subsection{Description}

The basis for our empirical network study is a unique historical data set on fine art auction transactions taking place in London-based auction houses between 1741 and 1913. The transactions were recorded in three volumes by the former art dealer Algernon Graves (Graves, 1918). We retrieved these three volumes from the Victoria and Albert Museum Library in London. The sample period is very important for the global art market as it marks the time span over which the market evolved to maturity (as we know it today). London was the focal trade location for artworks in the 19th century and the beginning of the 20th century (Bayer, 2015). Further, it also constitutes the period when the profession of art dealer emerged.

Overall, the data set comprises of 37,640 transactions. Historical records indicate that the data set is a representative sample of auction sales over this period (Bayer, 2015). All transactions took place in an English auction format in which the buyer with the highest bid receives the item. Only the final hammer prices are observed. This implies that, for every auction, the winner and the final bid are known. The unique feature of the data set is the availability of the original sellers' and buyers' identities in the transactions. Besides this, we have information on the name and living status of the artist, the name of the artwork, its size and genre attribution. In addition, transaction data are available, including the name of the auction house where the sale took place, whether the transaction was part of a collection sale, the date of sale and, lastly, the nominal sales price in pounds, shillings and pence. We do not have information on either the number or the identities of losing bidders at these auctions but we have information on rival winners in the same auction sale who were likely competitors. A number of the aforementioned variables were used as individual artwork characteristics to control for the quality of the artworks. An overview of the variables can be found in the Appendix in Table A1. Another virtue of the data is that during that time the lot sequence followed an alphabetical order based on the name of the artist as opposed to the popularity or the value of an artwork which is common nowadays. As a result, lot allocation is random in our data set. Moreover, all bidders had to be physically present to participate in the auction sale. Therefore, all auction participants were aware about the identity of their competitors which should have impacted their bidding strategies. 
We restricted our analysis to buyers who were professional art dealers and acquired artworks with the goal of reselling them for a profit in the future. Whereas emotional and aesthetic aspects might drive purchases of private collectors, we were only interested in buyers who did not derive personal utility from holding an inventory of artworks. Therefore, throughout the analysis, we use the terms dealer and buyer interchangeably. As the data did not provide any biographical information on the buyer, we used museum archives to identify professional art dealers. ${ }^{4}$ Further, we excluded observations in which the sales price was missing, buy-ins ${ }^{5}$, as well as transactions in which the buyer and seller were the same person. ${ }^{6}$ This left us with a sample size of 17,479 observations spread over the period March 1741 to December 1913. The sample consists of 25 auction houses, 1,099 artists, 3,187 sellers and 137 buyers who were identified as art dealers. ${ }^{7,8}$ The majority of our variables were consolidated on a monthly basis. As there were no transactions in some months, we end up with 811 time periods (months) in our sample. In the exit analysis, the data is consolidated on a yearly basis.

Art auctions represented the most important source of supply for art dealers and, moreover, were sensational public events. Therefore, the majority of buyers were art dealers who repeatedly purchased at auctions to replenish their inventory. Overall, art dealers purchased $46.4 \%(17,479)$ of all artworks traded at auctions in terms of volume. However, it was unusual for art dealers to sell at auctions. ${ }^{9}$ As market makers, the goal was to resell the acquired artwork to their clients. Auction sales by dealers are rarely observed in the data. Out of 37,640 artworks that were transacted at auction 1,613 (4.3\%) were sold by art dealers. A large fraction of sales comprised of estate sales. Many of these were prestigious collections (e.g. the Orlean's collection) which were owned by influential personalities; among them many aristocrats and members of the high society. Thus, sellers mainly consisted of non-professional traders who used auctions to liquidate property. However, while sellers used auctions as a sales platform, purchases were rather made through art dealers. Therefore, even

\footnotetext{
${ }^{4}$ The historical nature of the data set limits on how much information could be extracted on the identities and biographies of the individual buyers. For instance, we cannot distinguish between full-time and part-time dealers. Moreover, we could not always distinguish businesses that discontinue due to mergers or partnerships. In cases in which dealerships were held by families over generations, we do not distinguish between different family members who managed the business in different ownership periods.

${ }^{5}$ In auctions, a buy-in takes place when an artwork is not sold as it fails to meet the seller's reserve price. In our data set, buy-ins represent only $5.6 \%$ of all transactions.

${ }^{6}$ Instances where buyer and seller were listed as the same person are difficult to interpret. These could be related to data entry errors or cases where a seller is submitting phantom bids or intervenes in the process to buy-in.

${ }^{7}$ Overall, there are 138 art dealers in the sample. However, we dropped the observation of a dealer who had a single sale through the period with an incomplete transaction record missing seller identity information.

${ }^{8}$ As mentioned earlier, Christie's auction house is capturing $97 \%$ of the market by number and by value of acquisitions.

${ }^{9}$ Most instances in which art dealers acted as sellers at auction were instances of business liquidation.
} 
though players can in theory participate in auctions as buyers and sellers, historical records as well as our data clearly show that they assumed either of these roles from the onset. For this reason, the network can be represented by a bipartite graph as described in Wasserman and Faust (1994) where nodes can be partitioned into different subsets. For a comprehensive overview of the art market of that time, the functioning of art auctions, as well as the profession of art dealers, see De Silva et al. (2016).

It is worth mentioning that we conducted research to identify references to potential collusion between art dealers throughout the sample period as it could impact the interpretation of our results. Dealers with a large network could also have more chances to collude with each other, creating added opportunities for profit. However, we could not find any anecdotal evidence of such cases in the historical records. There is a discussion of ring activity (Cooper, 1977, p. 88) in the 1920's but this discussion does not cover our sample period. Even though we cannot rule out the existence of instances of collusion, the possibility of such activity in our extensive data set may point to an alternative channel by which a network provides benefits but does not alter the conclusion that developing a network is beneficial to the dealer. In our analysis, we use a different approach and identify large and small dealers by their volume of transactions to study the relative impact of a connected dealer on auction prices.

Our data set, comprised of fine-art auction transactions spanning a period of a century and a half, offers a valuable real-life application for network analysis. Using the emerging art market network as a case study, we can learn about the competitive strategies of professional dealers that lead to sustained market success. The following two subsections will detail our constructed network measures, the characteristics of the network structure, as well as individual dealer characteristics.

\subsection{Network Measures}

Given the data set, we are facing a link formation setting where a buyer can decide to form a link with a seller resulting in a bipartite network. In order to define the structure of the dealer network in more detail, three different measures were constructed which are derived from the trading intensity of the network participants. The measures include the number of direct links for buyers

and sellers, the number of same-pair transactions, and the number of common connections. While the number of direct links is an individual-specific count, the number of same-pair transactions, and 
the number of common connections are both link-specific. In order to avoid underestimating the size of the network, all measures were constructed using the full sample which also included buyers not identified as professional dealers.

For our first measure, the number of direct links, we counted the number of transactions with distinct trading partners per month and let it accumulate over time. This measure is individualspecific, meaning that her connections were counted independent of whether she assumed the buyer or seller side in a transaction. Our second network measure is the number same-pair transactions. The measure was constructed by counting the monthly number of transactions per buyer-seller pair and letting it accumulate over time. Our last measure is the number of common connections. This measure aims to compare the networks of trading partners, giving an indication of how dense the network is. To determine this count, we calculated the number of exchange partners both agents have traded with, in the past. Given the long sample period as well as the fact that professional art dealers were smaller in number (137 distinct dealers) as opposed to sellers (3,187 distinct sellers), we expect an overall higher number of direct links for buyers than for sellers. There is still, however, a considerable number of instances of sales by individual sellers. In particular, a seller appears on average in two different periods (months) at auction and, out of 3,187 sellers, 1,924 (about 60\%) submitted at least two artworks for sale. Moreover, as mentioned before, many sellers were influential members of the high society. Therefore, established links to these individuals, could provide art dealers with further opportunities for information and thus profit. Additionally, since some of the dealers had a presence in the market that extended over many decades, we also considered limiting attention to the last 10 years of transactions and assumed that a network connection lasted for an amount of time more limited than the dealer's duration in business.

Table 1 lists the number and value of acquisitions as well as the counts for the network measures for the top twenty-five dealers based on the number of acquisitions for the entire period. ${ }^{10}$ We can see that the dealer Agnew is by far the largest dealer in the sample in terms of all measures. He captures $34 \%$ of sales by the number of acquisitions and $44 \%$ in terms of value of acquisitions. Moreover, his number of direct links (938) is more than double the amount of the dealer with the second largest number of direct links (Colnaghi with 413 connections). As a result, Agnew forms the center of the dealer network. Overall, the twenty-five largest players own $75 \%$ of all connections

\footnotetext{
${ }^{10}$ All prices are in constant $£ 1900$ and were converted using the UK CPI provided by the Bank of England.
} 
in the network. The number of common connections, which is not depicted in the table, reaches a maximum of 2. Information dispersion among the dealers is limited through the auction process. On the other hand, the benefits of connecting with a new player decrease if the distance to the indirect network is too large (Bala and Goyal, 2000). Further, repeated exchanges among the same pair have a moderate frequency. Agnew interacts on average 5.3 times with the same seller, while the average dealer interacts 1.7 times with same trading partner at auction.

Figure 1 visualizes the development of the whole dealer network from 1800 until 1880 which represents the peak of the market in terms of market volume and number of dealers. Figure 1(a) depicts the network at its onset in 1800 . Overall, there are only a few dealers with a few interactions. Its structure is clustered, with one large network in its center (headed by the dealer Bryan) and a handful of peripheral smaller networks around it. The future market leader, Agnew, is already present in the market but, with one link, is still a small player. In Figure 1(b) we can see how the dealer network evolved after 20 years. The number of market participants and the number of dependencies between individual players have increased. While we are facing a bipartite graph, some dealers are indirectly connected to each other through trades with the same sellers. Further, we can observe a higher number of very large and peripheral players. The dealer Seguier surpassed Bryan as the largest market player. Agnew still remained a fringe player with one link and Colnaghi, the second of the future top three dealers, now appeared at the periphery with one connection. Finally, Figure 1(c) presents the network in 1850, before its peak. ${ }^{11}$ The complexity of the network increased with many links between players. All three future top dealers, Agnew, Colnaghi, and Vokins are now in the market. While Agnew and Colnaghi managed to grow their respective networks, they are a lot smaller than the top three players-Smith, Nieuwenhuis, and Seguier-in terms of established links. Overall, the number of larger players grew within an emerging dynamic market structure. Lastly, Figure 1(d) shows the network at its peak, in 1880. The complexity of the network has risen drastically. There are several hubs and a very large number of peripheral players. Agnew has developed into the largest dealer in the market followed by Vokins, Graves, Smith, and Colnaghi. Figure A1 in the Appendix presents the full network which is highly complex. It is highly unequal, dominated by a few large hubs, loosely connected to one another and many isolated networks on its outskirts. Given the large number of nodes, the number of links is rather small. Moreover, dealers

\footnotetext{
${ }^{11}$ We show the year 1850 instead of 1840 , as this is the time when the second largest player, Vokins, enters the market.
} 
are mostly not directly connected. Instead, dealers are indirectly connected to one another through the common sellers they interact with. As a result, the interconnectedness of the network is low and the market withdrawal of one large player would not impact significantly the whole market. As such, a shock would not easily spread to indirectly connected networks that are located further away. However, the consequence of a shock could cause price volatility due to oversupply as a large amount of offered artworks might not be able to be absorbed by the remaining players.

Eventually three players, namely Agnew, Colnaghi, and Vokins, form the hubs of the network with a very large number of connections. Figure 2 shows the overall number of dealers in the market over time as well as the evolution of the network for the three largest players compared to the other dealers. Figure 3 depicts the number of dealers by the years of market exposure. The distinction between time and years of market exposure is important as the three key dealers did not emerge at the same time. Also, while the number of dealers sharply increased over time (Figure 2(a)), it gradually decreased with the years of market exposure (Figure 3(a)). Only 12 dealers remained in the market for 100 years or more; among them Agnew and Colnaghi. The large jump in the amount of dealers at around 1870 which can be observed in Figure 2(a) coincides with rising market prices and trading volumes of artworks sold via auctions. This was also the time when local contemporary artists gained in popularity and established themselves in the market (Bayer, 2015). Interestingly, as shown in 2(b), the number of the networks starts to grow at around 1850. While the mean number of connections was 10 before 1850, it jumped to an average of 64 during the period 1850 to 1913. For instance, the number of Agnew's direct links reaches the cumulative amount of all other dealers' number of links at around 1880. This coincides with the time period when dealers successfully managed to establish national, contemporary artists in the market. As market makers, they could exert more control on local living artists than Old Masters which occasionally turned out to be forgeries (Bayer, 2015). The same pattern can be observed in 3(b). As Vokins entered the market later than Agnew and Colnaghi, his number of direct networks starts growing after a very short period in the market. This graph also indicates that the number of direct links of all other dealers remained fairly stable over time. ${ }^{12}$

Figure 4 visualizes the size of the networks of Agnew, Vokins, and Colnaghi in 1850 (Figure 4(a)) and at the peak of the art market in 1880 (Figure 4(b)). All three players grew their networks

\footnotetext{
${ }^{12}$ Figure 2(b) depicts the cumulative number of direct links for other dealers, while Figure 3(b) shows the average number of buyer links for other dealers.
} 
substantially within 30 years. In 1850, Agnew was already the largest of the three dealers. Unlike Agnew, Colnaghi and Vokins shared one common connection which might have helped them to acquire new links and improve their relative competitive positions. By 1880, the three agents are a lot more interconnected and Vokins overtakes Colnaghi in terms of the number of links. These three players would remain the strongest dealers in the market from the year 1880 onward. ${ }^{13}$

\subsection{Homophily Measure}

The similarity between two market players can influence the likelihood of an exchange as well as the conditions of the trade (Currarini et al., 2009). The tendency to form connections with agents who are alike in their characteristics is termed as 'homophily' in the network literature (Jackson, 2010). Within the setting of fine art auctions, the most sensible attribute based on which buyers and sellers can be compared, is their trading pattern across different artistic genres. Art dealers might have aimed at developing product-specific knowledge by specializing in certain genres in order to promote particular artists and tailor to certain customer segments. Sellers were often in possession of themed collections providing them with knowledge in certain artistic styles. Overall, we identified nine different genres in our data set. The artworks that could not be attributed to any genre were subsumed under the heading 'other'. ${ }^{14}$ All categories can be found in the Appendix in Table A1.

Table 2 shows summary statistics for the different genres. ${ }^{15}$ In terms of volume and value of sales, the genre Landscape by far outperforms all other genres. With 5,024 sales, it reaches almost twice as many sales as the second most popular theme of Genre (2,741 unit sales), closely followed by Religion (2,377 unit sales). ${ }^{16}$ Landscape was a very popular genre for English contemporary artists who were heavily promoted by dealers at that time. A famous representative of Landscape paintings was the artist William Turner who is very well represented in our data set with 981 sold artworks. Less popular themes were Marine, Mythology, and Portrait paintings. In particular, Mythology and Portrait paintings can be attributed to the Old Masters, which art dealers tried to demote in the market (Bayer, 2015). This is also reflected in total sales in terms of value. While more than $£ 2$

\footnotetext{
${ }^{13}$ Due to the historic nature of our data set and lack of information on individual transactions outside the auction market, we do not preclude the possibility that we do not capture all links and, therefore, might underestimate the extent of the network reach.

${ }^{14}$ This category includes, for instance, sculptures.

${ }^{15}$ All prices are in constant $£ 1900$ and were converted using the UK CPI provided by the Bank of England.

${ }^{16}$ The genre 'Genre' includes artworks depicting scenes and activities of everyday life. Portrayed persons are not clearly identifiable or well-known individuals.
} 
million worth of Landscape artworks were sold, only $£ 1.2$ and $£ 1$ million respectively were spent on Religion and Genre artworks. Interestingly, average values for Old Master genres such as Religion (£504), Mythology (£456), and Still Life (£409) are higher than the average prices for Contemporary art such as Landscape which sold, on average, for a mere $£ 388$ per artwork. This might be explained by the scarcity of Old Masters relative to contemporary artworks. The genres that are bought by almost all of the 137 art dealers in our sample are Landscape (118), Religion (107), and Genre (106). By contrast, Portraits and Marine paintings were only bought by less than half of the dealers in the sample.

These observations indicate that dealers were not highly specialized. Almost all dealers traded in Contemporary art and filled up their portfolios with some Old Masters to hedge the risk of representing new artists. The artistic genres with the highest number of different sellers are Landscape, Genre, and Religion. This means that ownership of the most popular genres appears to be rather dispersed. The popularity of these themes is also reflected in the amount of distinct artists in each genre. Oftentimes, artists were even known for a signature subject or style (e.g. William Hunt's Bird Nest). This made an artist more recognizable and competitive in the market for Contemporary art (Bayer, 2015).

In order to construct our measure of similarity, we first determine each market player's specialization by computing the share of artworks she bought and sold in every genre as a percentage of her overall sales and purchases in terms of volume accumulated over every period. Table 3 shows summary statistics for the buyer and seller specializations by genre. With an average specialization of $35 \%$ and $37 \%$, the genre Landscape was the most popular specialization for art dealers as well as for sellers. The second highest share of purchases accrued to Genre paintings. However, the sales share of this genre is $19 \%$ - approximately only half the size of the share of purchases of Landscape paintings. The least popular specialization was Still Life which, on average, accounted for only $2 \%$ of buyer and seller trades. Overall, both buyers and sellers followed the same trends in their specializations. The share differences never drift further away than $2 \%$ as is the case for Landscape paintings, where sellers were more specialized than buyers. This can be explained by the fact that this was a Contemporary genre which enjoyed high popularity and was, therefore, sometimes sold by the artists themselves at auction.

In order to obtain variables that capture specialization differences, we constructed three measures 
which will be used in different parts of our analysis. The first one is an overall homophily measure that takes into account the information on trades across all genres. It indicates how similar the buyer and seller are with respect to their purchases and sales volumes. A more similar trading pattern should result in a higher probability to form a link. The measure is defined as the root mean square deviation, i.e., the square root of the sum of the squared differences in the share between buyer and seller for all genres. The resulting value is strictly positive with a lower value indicating a higher degree of similarity between buyer and seller. The second measure relates to the buyer's and seller's specialization within one particular genre. This variable aims to compare trading partners based on their main area of expertise. For every period and agent, we determined the genre with the highest share and subtracted the trading partner's respective share in that genre. The absolute value of this number indicates the size of the distance between buyer and seller with respect to the genre they are specialized in. The value is always positive and ranges from 0 to 1 . A higher value points to a larger distance between the agents. These two measures, the homophily and the genre specialization difference measure, will be used in the network formation analysis. A dummy variable indicating the dealer's specialization is employed in the exit analysis.

The third measure is an object-specific specialization difference. Based on the genre of the artwork that is up for sale, we subtracted the seller's share in that genre from the buyer's share in that genre. The value can range from -1 to 1 . The closer the value is to 1 , the large the information leap of the buyer relative to the seller. This measure is used in the bidding analysis and proxies the informational advantage of the buyer relative to the seller. All measures are dynamic and updated periodically throughout the analysis.

It is important to note that, in the empirical analysis, we used lagged values of the buyer's specialization and contemporaneous values of the seller's specialization to construct the three measures mentioned above. As auction houses released catalogs listing upcoming sales, the seller specialization was publicly known some time before the auction sale. By contrast, the buyer's specialization before trade takes place depends on her history of purchases up to this point. Therefore, we use lagged 
values of these variables for buyers. ${ }^{17}$ Summary statistics will be presented in the empirical analysis.

\section{Empirical Analysis}

\subsection{Network Formation}

We start our empirical analysis by investigating the factors that influence the probability of link formation between buyers and sellers. In each period, a buyer has the opportunity to form a link with each seller, considering the set of all possible choices. A link is established if a buyer transacted with an individual seller at least once in a given period. A buyer is considered to be in the market from the time period of her first purchase until the time period of her last purchase even if she is not active in all periods. In our data set, we have 137 unique dealers and 3,187 unique sellers with 6,194 connections among the set of 242,145 potential links. Therefore, our data set includes all potential seller-buyer combinations in each period ending up with a sample size of 242,145 observations.

Our dependent variable is equal to 1 if a buyer, in time period (month) $t$, forms a link with a seller and 0 otherwise. The buyer will only form a connection if it is beneficial to her which will depend on the existing networks, the individual node characteristics, as well as the reputation of the seller. We assume that participants are aware of the shape of their current network but have no information with respect to its future shape.

Based on the prediction in our model related to the impact of better information on prices and profits, we expect that a higher number of direct links formed in the past will positively influence the formation of new connections. Hence, we are interested in modeling the probability, $P_{j, t}\left(l_{t}, N_{j, t-1}, D_{j, t}, R_{l, t-1}, g_{j}\left(N_{t}\right) ; \theta_{t}\right)$, of a link established by buyer $j$ to seller $l$ as a function of an unknown vector of parameters denoted by $\theta_{t}$ at a given time. We use observed data of the structure of the network $N$, bidder market exposure $D$, seller reputation $R$, and the homophily measure $g(N)$ and postulate a prior distribution for $\theta_{t}$. We then derive the posterior distribution for $\theta_{t}$ and calculate the probability of link formation for different values of $N_{j, t-1}, D_{j, t}, R_{l, t-1}$, and $g_{j}\left(N_{t}\right)$.

\footnotetext{
${ }^{17}$ The use of the lagged values of these variables results in a zero entry for the first transaction of a buyer. However, given that information on artworks was provided upfront through auction catalogs and that the buyers in our sample were professional dealers, it is unlikely that a buyer had no information at all upon her first purchase. For this reason, we impose a value of 0.1 for the first transaction in the respective genre across all buyers presuming that a dealer starts with an equal specialization in every genre. A share of 0.1 was selected as there are 10 artistic genres in the data set. The share of the sample that was modified this way amounts to $0.37 \%$. An alternative solution is to replace the zeros for buyers with the global mean in that respective genre. Using this specification of the variables leaves all results in the empirical analysis unchanged.
} 
As one could question whether once established links continue to be relevant over the entire lifetime of an agent, we employ an alternative specification of the variable in which the informational value of links ceases after a 10-year period. Further, the more frequent is the interaction between a buyer and a seller and the higher is the number of common connections the higher should he the chance of forming a link. Since capacity is highly correlated with the number of direct links ${ }^{18}$, we include a seller's capacity instead of the number of direct seller links as an explanatory variable in the link formation analysis. This variable is a proxy for the reputation of a seller. Given the fact that a lot of forgeries and artworks in poor condition were circulating, the track record of a seller was of high importance.

With respect to genre specialization, we expect that the more similar the buyer and the seller are in their trading patterns and genre specializations, the more likely they are to trade with each other in an auction setting. In this part of the analysis, we use the homophily measure as well as the absolute distance between the buyer and the seller with respect to their genre specializations. The former measure captures the similarity in trading patterns across all genres between the buyer and the seller; the latter measure proxies for the distance in the genre the trading partners are specialized in. Lastly, we consider the level of an agent's market exposure which proxies for her market experience. The variable is defined as the number of years since her first appearance in the market. Our dependent variable is binary, indicating whether a link is formed or not.

Based on the utility of forming a link, broadly outlined in the theoretical section, we consider an empirical framework defining the probability to form a link between $j$ and $l$ to buy artwork $i$ at time $t$ as

$$
\begin{array}{ll}
\ln \left(\frac{P_{j, t}\left(l_{t}, N_{j, t-1}, D_{j, t}, R_{l, t-1}, g_{j}\left(N_{t}\right) ; \theta_{t}\right)}{1-P_{j, t}\left(l_{t}, N_{j, t-1}, D_{j, t}, R_{l, t-1}, g_{j}\left(N_{t}\right) ; \theta_{t}\right)}\right)=\quad & \gamma+\beta^{\prime} N_{j, t-1}+\delta D_{j, t}+\rho R_{l, t} \\
& -\left(g_{j}\left(N_{j, t-1}-N_{l, t}\right)^{\prime} \Psi\left(g_{j}\left(N_{j, t-1}-N_{l, t}\right)\right)\right. \\
& +\epsilon_{j l, t}
\end{array}
$$

where, as mentioned earlier, $N$ is the network structure, $D$ represents bidder market exposure (age), and $R$ is the seller's reputation as this is expressed by the value of previous transactions. The

\footnotetext{
${ }^{18}$ The correlation between capacity and number of direct links is above 0.871 .
} 
term $\left(g_{j}\left(N_{j, t-1}-N_{l, t}\right)^{\prime} \Psi\left(g_{j}\left(N_{j, t-1}-N_{l, t}\right)\right)\right.$ is the disutility of having a difference in the specialization between potential partners which relates agent $j$ in period $t-1$ to a function of the number of previous purchases of artwork in the same genre (see Christakis et. al 2010 for a similar measure of homophily). $g$ is a measure of homophily that is expressed in one specification as the standard deviation of the trades across all genres and in another as the relative buyer/seller specialization in a specific genre. $\Psi$ is a diagonal matrix. We assume that the $\epsilon_{j l, t}$ s are independent across all $j$ and $l$ at a given time, $t$, and that they follow a logistic distribution.

In the spirit of Christakis et al. (2010) for empirical link formation analysis, we used Bayesian estimation to obtain posterior values for each network parameter based on prior information on link formation choices. Within the Markov-Chain-Monte-Carlo methods, we selected the MetropolisHastings algorithm to update the vector of the parameter given the sequence of link formation. Unlike Christakis et al. (2010), we take advantage of the full data set instead of taking random draws from the samples. This is possible because, in our case, the average number of potential links is about 560 (56 dealers and 10 sellers) per period with a maximum of 2,964. Therefore, we do not encounter any computational constraints during the estimation of the model. Our analysis of link formation focuses on one side of the market (the buyer's side). Sellers decide to sell through an auction house, almost invariably Christie's and then buyers link to one of the sellers. Therefore, sellers are considered passive actors in our setting as they have no decision power with respect to the link formation. ${ }^{19}$ An independent normal distribution is specified for all parameters, with a prior mean equal to zero and a prior variance equal to one. The posterior estimates will provide a distribution for every variable in our model predicting link formation. The posterior means will be included in the second step of our analysis where we determine the effect of competition on price. This allows us to address endogeneity concerns related to the use of the actual number of direct buyer links in the regression. Consistent with our objective, a Bayesian approach offers the advantage of continuously updating posterior estimates given prior information on link formation and network characteristics.

Table 4 shows the summary statistics of all variables used in the Bayesian estimation. The number of potential links varies from period to period and depends on the number of transactions as well the number of buyers and sellers in that period. The unconditional average probability for

\footnotetext{
${ }^{19}$ Seller could only influence the sale by setting a certain reservation price upfront which would preclude the artwork to be sold below a certain value.
} 
a buyer and a seller to form a direct link is $4.9 \%$. With a mean value of 33.55 the number of direct buyer links is rather high. However, the large standard deviation (78.26) exemplifies the differences in the degree of connectedness of different dealers. The average number of direct links falls to 13 when we consider a 10-year window. A buyer's market exposure is also quite high with an average of 38.221 years. Again, the large standard deviation (29.308) accentuates the large variations in the dealer's years of participation at auction. Homophily, or the similarity in trading patterns between buyer and seller, is rather low with an average distance of 0.625 . Similarly, a mean value of 0.338 for the differences in the specializations between buyers and sellers shows that the agents are only moderately alike with respect to their specializations.

Table 5 presents the means and confidence intervals of the posterior distributions of our model parameters. We utilize a different time threshold for network formation; in column 1 and 3 the individual-specific network variable (number of direct buyer links), the buyer's market exposure, the same pair transactions, and a link-specific network variable representing the common links is based on the entire network formed through the years a dealer was actively bidding at auctions. In column 2 and 4 the network formation is based on the last 10 years' transactions. Limiting the lifetime of a link represents a more realistic assumption with respect to the process of link formation and maintenance, limiting the capacity to retain institutional memory. Further, while the models in columns 1 and 2 include our homophily measure, in columns 3 and 4 the absolute value of the genre specialization difference variable is employed to proxy the similarity between buyer and seller.

The results across models reveal several important observations. First, the buyer-specific network variable, the number of direct links, plays a significant role in explaining link formation. In all specifications, the mean of the posterior distribution is between 0.796 and 0.993 and the $95 \%$ confidence interval for the number of direct links lies strictly in a positive range of values. This indicates that a higher number of direct links increases the likelihood of forming a connection. Next, the number of same-pair transactions and the past number of common connections are also predictive of link formation. The mean of the distribution of the covariate is positive, contributing to the probability of establishing a link. The $95 \%$ confidence interval for all estimates is in the positive domain. The mean effect of the past number of direct buyer links and the past number of common connections based on the posterior distribution becomes slightly weaker when a 10 -year moving window is considered. Further, a higher level of market exposure decreases the likelihood of network formation. Thus, it 
appears that younger dealers are more eager to build a larger network than seasoned ones. This is intuitive as expanding a network might be more crucial during the establishment phase of a dealer in the market. The measure of the distance between buyer and seller, homophily, and the difference with respect to genre specialization, exhibit a negative effect on link formation. Homophily, which takes into account the distance across all genres, appears to have an even stronger adverse effect on link formation than the difference in genre specialization. Overall, in line with our expectations, it is less likely for players to form a link if they are specialized in different genres. Similar conclusions are drawn by the estimates in column 2 even though limiting the network formation period weakens the direct link effects and strengthens the significance of same-pair transactions.

Figure 5 shows the plot of the number of direct buyer links based on the full network. The graph shows the actual distribution of the values versus the predicted values. As can be seen, the lines are very close and lie almost on top of each other. Slight deviations are only observed for the lower end of the distribution. Considering the goodness of fit of the Bayesian estimates, the trace plot of the constant demonstrates good mixing. The posterior distribution of the constant is normally distributed, as is expected for the specified likelihood and prior distributions. ${ }^{20}$

Overall, it appears that the existing network features and the homophily are important predictors of link formation. In line with our expectations, a larger dealer network increases the odds of forming a connection. Also, the link-specific history plays an important role. More interactions among the same buyer-seller pair in the past, directly or indirectly through common connections, increases trust and lowers information barriers. As a result, the utility of link formation increases. The same applies to more similarities in product specializations, which make link formation more likely. Lastly, dealers with less market experience appear to be more eager to form links than more experienced ones. Having established the determinants for network formation, the next section will empirically investigate the role of network effects on the final hammer price.

\subsection{Bidding}

In this section, we examine how the features of a network and a player's characteristics affect prices. In particular, based on the theory outlined in section 2 , we expect that, with more direct links in a common value framework, a dealer should pay a lower price due to superior information on market

\footnotetext{
${ }^{20}$ These figures have been omitted but can be provided upon request.
} 
conditions. Further, a well-connected buyer could have knowledge of better outside options. Once more, we add model specifications using a 10-year moving window for network formation to be more realistic with respect to the time span of maintained knowledge from established links. Repeated interactions with various sellers provide experience that could set conditions for more attractive terms, informing her value assessment of the artwork up for auction. As mentioned earlier, because of the low variability in the number of direct seller links, we proxy seller reputation with financial capacity. A seller whose artworks obtained higher prices in the past, has credibly signalled the superior quality of his artworks to the market. As mentioned before, a lot of forgeries and artworks in bad condition were circulating in the market. Therefore, the variable can be regarded as a proxy for the seller's reputation. This measure is defined as the maximum total amount spent in any of the past periods. ${ }^{21}$ We expect a positive impact on price with higher seller capacity. Further, we expect that repeated exchange with the same seller should lead to better flow of information between the buyer and seller which could result in better terms of trade. On the other hand, a greater number of common connections will increase the information flow across bidders putting upward pressure on prices. With respect to the extent of genre specialization, we expect that the more specialized a dealer is compared to the seller, the lower the price she will pay at auction. A dealer who trades more heavily in a certain genre should have more information and command market power that allows her to extract higher rents. While auction catalogs were accessible to all agents, the possibility to physically inspect the artworks prior to the auction sale was not institutionalized during this time period as it is the case today. Therefore, the dealer's network and experience were crucial in assessing the artwork's value.

In this part of the analysis, we introduce additional control variables related to auction and rival characteristics. As these might have a considerable influence on artwork prices, they could confound the effect of network measures. Control variables related to auction characteristics include the number of bidders and the lot sequence within a single auction sale. A single auction sale is defined as a sale that took place during one day, in the same auction house, involving sales commissioned by the same seller. As we cannot directly observe the number of bidders competing for individual artworks, we proxy competition in two ways: 1) We estimate the number of competitors in an auction by summing up the estimated probabilities of all active bidders linking to seller $j$ to buy item $i$ at time $t$

\footnotetext{
${ }^{21}$ Again, this variable is consolidated at the individual level.
} 
and alternatively, 2) by the number of bidders who bought lots within the same auction sale. These rivals had access to the same catalog that listed all the items in a single auction sale and were likely present throughout the duration of the auction sale that day. ${ }^{22}$

The number of potential rivals can increase competition in an auction and lead to higher prices (Li and Zheng, 2009). Moreover, the timing when an artwork comes up for bidding within a sequence of lots can influence the price. While there is empirical evidence that early lots fetch lower prices than later lots (Chanel et al., 1996; Deltas and Kosmopoulou, 2004; Pesando and Shum, 1996), there is also research showing that later lots may yield lower prices (Ashenfelter, 1989; Ginsburgh, 1998; Ginsburgh and van Ours, 2007). In common or affiliated value environments, the release of information in the lot sequence reduces uncertainty and leads to higher prices (Milgrom and Weber, 1982). The attributes of the rivals faced by an art dealer at auction could also affect her strategy and, as a result, influence artwork prices. Therefore, we control for the rival's maximum capacity and market share in terms of volume. The rival's maximum capacity is determined by identifying the highest financial capacity among all winners within a particular auction sale. Again, financial capacity is defined as the highest amount ever spent by a bidder in the past. The rival's maximum share by volume is identified in the same way with the rival's accumulated market share in terms of purchased items being the value of interest. This is a more consistent measure for market power than financial capacity as it cannot be distorted by one large purchase. The rationale for both control variables is that the presence of wealthier bidders or bidders with more market power might have a positive effect on auction prices. Alternatively, we use the average past number of distinct links of the rivals in the same auction sale. This number is an alternative measure of rival competitiveness that focuses on access to proprietary market information. They all relate implicitly to the vector of signals $\mathbf{Z}$ in the modeling section. To control for the quality of the artworks, we include their characteristics in our regression model..$^{23,24}$ Furthermore, we include buyer and year fixed effects. ${ }^{25}$

We run a simple linear regression with the logarithm of the price as our dependent variable.

\footnotetext{
${ }^{22}$ In instances where the number of bidders was smaller than three, it was replaced by the number of lots sold during one day independent of the identity of the seller.

${ }^{23}$ These characteristics are referred to as hedonics and include the name of the artist, her living status, the medium of the artwork, whether the artwork was part of a collection sale, and the auction house where the transaction took place. These are commonly accepted attributes determining the quality of artworks in the art economics literature (Ashenfelter and Graddy, 2011, 2003; Hodgson and Vorkink, 2004; Rosen, 1974; Velthuis, 2013)

${ }^{24}$ Even though the size of an artwork has a considerable explanatory power over price, the variable is excluded in the regressions due a high number of missing observations. The large drop of the sample size would lead to a misrepresentation of the true network.

${ }^{25}$ As we are using year-fixed effects, we do not adjust the price by the UK CPI.
} 
All network-related explanatory variables are transformed into their logarithms and lagged by one period. Due to endogeneity concerns we introduce in one specification the expected number of bidders obtained from the Bayesian estimation of the probabilities to form a link with a specific seller at time $t$. Our basic regression model has the following specification,

$$
\ln P_{i j, t}=\gamma^{\prime} N_{j, t-1}+\vartheta D_{j, t-1}+\sigma S_{i}+\zeta R_{l, t}+\eta^{\prime} M_{j, t-1}+\beta^{\prime} X_{i}+\alpha_{j}+\tau_{t}+\epsilon_{i j, t},
$$

where $\ln P$ indicates the $\log$ of the price of an artwork, $i$, bought by dealer $j$ in a given year $t$. As before, all network effects are captured in $N$. The dealer's market exposure is represented in $D$. The object specific specialization difference between buyer and seller is represented by $S$. $R$ is the seller's reputation, $M$ represents the rival characteristics, and $X$ denotes the artwork's characteristics. $\alpha_{j}$ and $\tau_{t}$ represent the dealer- and time fixed-effects. Lastly, $\epsilon_{i j, t}$ denotes the error term.

Table 6 shows the summary statistics used in the OLS. Unlike Table 4, here we consider the dealers who actually bought artwork in a specific period. The mean value for the predicted direct buyer links is 226.826 with an even larger standard deviation. The number falls to 94.218 when a 10 -year moving window is considered. With a mean of under 61 years, the average market exposure is quite sizable. However, this number is likely to be driven by some large dealers. The mean of the number of same-pair transactions and the number of common links are 1 and 0.123 respectively. Further, on average, the buyer is less specialized than the seller at the level of individual artworks. However, the difference of $7.2 \%$ is of very small magnitude. Seller capacity is, on average, about $£ 2,603.326$ with large differences between the agents (standard deviation of $£ 8,149.814$ ). The average number of bidders, who won at least one lot in an auction sale is 11.238 while the average number of lots offered is 16.871. The rival's maximum capacity lies, on average, at $£ 1,135.04$, while the maximum market share, in terms of volume, is $2.8 \%$. Both numbers have a considerably high standard deviation.

The results of the bid regressions are reported in Table 7. While columns 1-3 consider a life-long duration of once established buyer links, columns 4-6 use a moving window of 10 years for buyer network formation. Columns 1 and 2 show the regression coefficients when the rival information is confined to measures constructed from competitors within the same auction sale. In columns 3, we incorporate information on expected competitors based on the likelihood of making a link that depends on their history of link formation. Specifically, due to endogeneity concerns, the 
predicted number of competitors is obtained from the Bayesian estimation based on the model specification used in columns 1 and 2 in Table 5. These specifications employ homophily (sum of the standard deviations of the specialization differences across all genres) as a proxy for the distance between buyer and seller. ${ }^{26}$ The results remain qualitatively the same and can be found in Appendix A in Tables A4 and A5. As we use the logarithmic transformations of all variables, the coefficients can be interpreted as elasticities. ${ }^{27}$ Overall, the results indicate that for the main model specifications (columns 1-3), the coefficient on the past number of distinct buyer networks is negative and statistically highly significant. The magnitude remains stable at around -0.160 . The result pick up slightly in magnitude and remains qualitatively the same when a 10-year moving window is considered (columns 4-6). Recent connections bring in more information that is relevant to the current transaction. In line with our expectations, repeated transactions between the same buyer and seller result in lower prices. Regardless of the model specification, the coefficient has a value of about -0.09 and is statistically highly significant. The last network-related variable, the past number of common connections, is statistically insignificant. This can be explained by the low magnitude and variation of this variable which limits upward pressures on the price and prevents the dissipation of the rents from proprietary information.

The buyer's market exposure is statistically and economically highly significant with a coefficient of about 0.223 in the main specifications (columns 1-3). Dealers who have a long history of participation at auctions tend to bid more aggressively. Further, the coefficient on capacity, the proxy for seller reputation, is close to zero and statistically insignificant. This can be explained by the large number of sellers as compared to buyers leading to many zero values when the variable is lagged by one period. The relative difference in the object-specific genre specialization between buyer and seller has a rather low impact on price in terms of statistical significance but an important economic effect. The larger the buyer's information leap over the seller in the traded object, the lower the price she pays at auction. However, the coefficient has only a weak significance in most specifications.

The auction and rival characteristics also exhibit an important influence on artwork prices. Both the number of bidders and the lot sequence are positive and statistically highly significant. In line

\footnotetext{
${ }^{26}$ As a robustness check, we repeat all regressions in this section using the model specification where the absolute difference in genre specialization was included in the construction of the predicted network measures (columns 3 and 4 in Table 5).

${ }^{27}$ We do not use a logarithmic transformation for the past number of common connections due to the low magnitude of the values of the variable which range from zero to two.
} 
with the findings of Chanel et al. (1996); Deltas and Kosmopoulou (2004), we show evidence that later lots are sold at higher prices. This could be an indication that bidders behave more aggressively as the auction comes to an end to avoid being left empty-handed but more importantly it is also consistent with behavior in a common or affiliated value environment. Given that the lot sequence is based on an alphabetical order as opposed to the value of the lots as it is commonplace nowadays, this result is particularly meaningful. The magnitude of the coefficient remains high across all specifications. The coefficient on the rival's maximum capacity is positive and highly statistically significant. It appears that competition from established dealers drives up prices at auction. However, a rival's market power in terms of market share by volume is statistically insignificant. More importantly, the expected number of bidders, estimated from the link formation model, is large in magnitude and statistically significant signifying that likely competitors in this market exert considerable pressure on the price. ${ }^{28}$

As the market in our sample is characterized by a small number of very active dealers and a large number of dealers who exhibit lower levels of activity, we are also interested in exploring whether network effects differ between these two groups. As referred to earlier in Table 1, Agnew, Colnaghi, and Vokins were historically the most important dealers of that time. These three dealers captured about $46 \%$ of the total number of acquisitions whose payments reached about $55 \%$ of all transacted value. Their average number of unique direct links reached 567 or 17 -fold the average number of links for all other dealers. To illustrate the differences across groups, we performed an additional regression analysis, splitting our sample into two sub-samples (see Table 8). While the first subsample excludes the largest three dealers in terms of volume of transactions (columns (1)-(6)), the second sub-sample examines bidding patterns for those three only (columns (7)-(12)). The results show that the effect of the number of direct buyer links more than doubles in magnitude for the top three dealers relative to that of the pooled sample exhibiting a much stronger effect on price. On the other hand, the coefficient decreases substantially for the sub-sample that excludes those top three. The importance of network size is also exemplified when we consider a sub-sample of the twenty-five largest dealers (see Table A2 in the Appendix). While the coefficient for the top three ranges between -0.389 and -0.532 across specifications, it only increases to values between -0.178 and

\footnotetext{
${ }^{28}$ In order to construct the variable expected number of bidders, we calculate the probability of a forming link at given time, for each auction participant, using the full sample. Then, we add the probabilities of all participants at a given auction to construct the expected number of bidders. This is similar to the approach taken by Hendricks et al. (2003).
} 
-0.217 for the top twenty-five (who have an average of 185.52 direct links) compared to coefficients of -0.156 to -0.182 for the full sample of dealers (who have an average of 45.09 direct links). Similar trends appear in other network-related variables indicating that, for large dealers, all network effects are more persistent. More importantly, as a robustness test on the value of proprietary information theory, excluding the sample of the 25 most dominant dealers by the volume of transactions, the network effects on the price become insignificant. The same pattern can also be observed for the variable on market exposure which more than triples in magnitude for the top three sub-samples. The only exception is the coefficient on the object-specific specialization difference which is insignificant for the sub-sample that includes only the top three dealers. A potential explanation is that these dealers are largely diversified and do not specialize in particular genres. Overall, this sub-analysis shows that having an extensive network is the key to long market presence for large dealers.

In summary, the results in this section provide strong statistical support that the buyer's network characteristics matter for artwork prices at auction. First, our findings stress the importance of the number of direct links as an explanatory factor in the prices paid by buyers. Art dealers who have a large network are able to acquire more information about the market conditions resulting in a competitive advantage that allows a further rapid expansion of their network. This allows the dealer to select the trade opportunities that yield the highest rent. Repeated interactions with the same seller make the trade cheaper as less additional information on the counterpart needs to be collected thus decreasing costs. Another effect results from the level of a buyer's specialization in a given genre. The informational leap gives the buyer market power and allows her to realize higher rents by paying lower prices at auction. This effect is, however, of low statistical power. Lastly, more rivalry for artworks from established buyers tends to drive up hammer prices. The next section, will investigate whether the lower prices paid by dealers with a superior network position also translate into a longer presence in the market.

\subsection{Market Exit}

In this section, we will explore whether a dealer's preferential position in a network also improves her chances to remain longer in the auction market. If a superior network indeed provides a dealer with a less noisy signal about the value of the artworks and results in higher profit margins, we expect dealers with a larger amount of direct links to stay longer in the market. The research on networks 
within the field of entrepreneurship shows that start-ups that receive support from a large and diverse social network are more successful. As a consequence, these firms are more likely to grow and survive in the market. A good network provides access to relevant information and resources and can substitute for human or financial capital (Brüderl and Preisendörfer, 1998; Dubini and Aldrich, 1991; Hoang and Antoncic, 2003; Raz and Gloor, 2007). For instance, Brüderl and Preisendörfer (1998) showed, in their empirical study on Munich-based business founders, that a start-up was more likely to survive and grow if it had support from a personal network. Similarly, in a longitudinal study, Raz and Gloor (2007) presented empirical evidence, in the case of Israel-based software start-ups, that suggested that a larger informal communication network increased their likelihood of surviving an external shock.

To measure the effect of the network characteristics on the dealer's likelihood to exit the auction market, a simple probit model is employed. In this part of the analysis, all variables are collapsed on a yearly basis. The binary dependent variable, exit, takes the value of one if the dealer exits the auction market in a given period and zero otherwise. Following the approach of De Silva et al. (2009), exit takes place upon the last period of appearance of the dealer in the sample. The last year in our sample is 1913. In order to track exits, we restrict entry by new dealers up until the last three years of the sample period. We consider a dealer who did not exit the market before 1910 as still active. A period of three years was selected as it should be a time period of sufficient length to assume that an agent has ceased her activity as an art dealer. We cannot exclude the possibility that she replenished her inventory elsewhere. However, given that auctions in London constituted the most important marketplace for art during that period, we consider inactivity in this market for more than three years as an exit. The results are robust if we use larger cut-off points of five or ten years to determine exit.

In this part of the analysis, our network variable of interest is the number of direct buyer links as it is the only individual-specific network variable. As in previous analyses, we also perform a robustness check limiting the lifetime of once-established links to 10 years. Furthermore, we introduce an interaction term between the number of direct buyer links and the dealer's market exposure. Figure 2(b) shows that the number of direct links for the top three dealers increases exponentially after a certain age. Therefore, for some dealers it might be the case that the number of links starts to rise at a higher rate after some time in the market. The interaction term accounts for 
this potential non-linear relationship between the number of links and a dealer's market exposure.

In addition to the number of direct buyer links, we also control for the dealer's average market share for the last three years in terms of value and volume. This allows us to account for a dealer's market power in the recent past. We expect that a higher market share will result in a lower exit probability. As these two variables are highly correlated, they are considered separately in different model specifications. Furthermore, we control for market competition by considering the number of rival dealers in a given year. As exit will depend on profit opportunities, this variable captures how attractive it is to remain in the market given the level of rivalry. Lastly, we account for the genre specialization of the dealers with a dummy variable. The variable takes the value of one for the genre in which the dealer has the highest market share in terms of volume. As mentioned before, there are overall ten possible genre specializations.

To ensure that the results are not driven by the three largest dealers - Agnew, Colnaghi, and Vokins - who remained in the market for an exceptionally long time, we perform a robustness check by excluding the top three dealers from the sample. The empirical specification of the probit model has the following form:

$$
\operatorname{Pr}\left(\text { Exit }=1 \mid W_{j, t}\right)=\Phi\left(\lambda^{\prime} W_{j, t}\right)
$$

where the independent variables in $\left(W_{j, t}\right)$ can be classified into three main groups $N_{j, t}, D_{j, t}$, and $M_{j, t} . N_{j, t}$ denotes the dealer $j$ 's network characteristics, $D_{j, t}$ represents the dealer $j$ characteristics, and $M_{j, t}$ includes rival characteristics based on the proxy used to assess the competitive landscape. $\Phi$ is the cumulative normal distribution.

Table 9 shows the summary statistics for the key explanatory variables. The average yearly number of direct links is 25.402 per dealer. It falls to 9.442 when we limit the lifetime of once established links to 10 years. In both cases, the standard deviation is rather high $(67.775$ and 23.498) indicating that there is large variability in the amount of direct links between dealers. The average market exposure is 34.28 years. The dealer's average market shares in terms of volume and value are in line with each other, both having a value of $2.4 \%$. There appears to be a larger variation between dealers when market share is calculated in terms of value. The mean of the yearly number of rival dealers is 53.748. Lastly, the average network size of the dealer's rivals in an auction amounts to almost 25 links. 
The results of the probit regression are reported in Table 10. Columns 1 to 4 present the results for the full dealer sample. Columns 5 to 8 show the result when the top three dealers are excluded from the probit regression. For all regression coefficients, we report the marginal effects. The results indicate that, independent of the selected dealer sample and the choice of the time window for link formation, a larger amount of direct buyer links decreases the probability of exit. More precisely, an additional direct link reduces the likelihood of exit by $0.7 \%$ in the base specification (column 1). Results remain approximately the same when a shorter time window for the life-time of links is considered (columns 2,4,6 and 8). Moreover, the coefficients also gain in magnitude when the strongest dealers are excluded from the sample (column 5 to 8). As in the previous section, when considering the top 25 dealers as opposed to the top three dealers (see Table A3 in the Appendix), the sensitivity of the probability of exit to the number of direct links becomes apparent. The effect increases by $0.2 \%$ (to $-0.9 \%$ ) for the top three sub-sample and it increases by $1.3 \%$ (to $-2 \%$ ) for the top 25 dealers. Further, it appears that the relationship between the number of direct buyer links and the dealer age is indeed non-linear. The interaction term is positive and statistically highly significant in all model specifications. This indicates that age alleviates the negative relationship between the number of direct links and the likelihood to exit. Stated differently, a high number of links becomes less relevant for business continuation with growing market experience.

The dealer's market share has a very strong negative effect on exit probability. The coefficient is large in magnitude and statistical significance in all regression specifications. The market share in terms of volume (columns 1 to 2 and 5 to 6 ) has a more important influence than the market share in terms of value (columns 3 to 4 and 7 to 8 ). As the latter can easily be driven up by a small amount of large acquisitions, it might be more indicative of a dealer's financial capacity as opposed to her market power. The number of rival dealers, which is defined as the total number of other dealers in the market in a given period, doesn't seem to affect market exit as it is statistically insignificant in every model specification. Lastly, the size of the dealer's rivals' network has a consistently positive effect on market exit of high statistical significance. It appears that a larger network indeed provides dealers with a competitive advantage, making it more difficult for other dealers to sustain a market presence. The fiercer competitive landscape decreases the potential for profits and drives dealers out of the market.

Overall, the findings in this part of the analysis show that a larger network results in a lower 
probability to exit the auction market. A larger number of direct links appears to enable the dealers to extract higher profit margins due to better information and more favorable conditions for trade. Furthermore, our findings provide evidence that the buyer's market power in terms of market share by volume is a decisive factor in her ability to sustain market presence. Lastly, it is not the number of competitors that affect the likelihood of exit but how connected they are.

\section{Concluding Remarks}

This is the first empirical study that applies network theory to auction data. Having access to a unique historical data set, which covers the period of the formation of the contemporary art market in the United Kingdom, gives us the opportunity to use the art market as a case study. We use the evolution of this market to investigate determinants for strategic link formation of art dealers which eventually affect the prices paid by different agents at auction. The virtue of network analysis is that it performs better in modeling human behavior in real life data, precluding the need for validating economic and behavioral assumptions (Kenett and Havlin, 2015). While traditional models enable us to only derive relationships between bidder specific characteristics and price, network analysis allows us to cope with the complexity introduced by interdependencies between different actors in the market. By taking into account the relative positions of buyers and sellers in the bipartite network, as well as the overall network structure, we can make more accurate predictions about the effect of individual players on price.

Our key findings provide insight into what drives link-formation choices of art dealers, how an agent's network influences the price of an artwork, and whether a preferential network position affects the dealer's likelihood to remain in the market. First, we provide empirical support that network structures appear to result not only from random shocks as proposed in early game-theoretic models. It seems that agents make profit-maximizing choices based on the market player's characteristics and the existing network structure. In particular, we find that network attributes, including the number of direct buyer links, the link-specific history, market exposure, as well as similarities in product specializations all drive the formation of new connections. These results are in line with Currarini et al. (2009), who find evidence for preferential attachment based on common attributes and with Iori et al. (2015), who show that repeated interaction leads to preferential link formation.

Second, the network structure can provide significant benefit to agents. A higher number of direct 
links results in lower prices paid by dealers. Through a larger network, more information can be retrieved on the competitive landscape, thus improving one's bargaining position. This is consistent with the empirical findings by Ozsoylev et al. (2014) who show that, in an investor network, central players perform better due to better access to information. In terms of the dealer's characteristics, the level of market exposure and the depth of product specialization have an impact on prices paid. While it is an established fact in auction theory that bidders can benefit from superior information at auction (Milgrom and Weber, 1982; Hendricks and Porter, 1988), to this point there is no evidence on the impact of a network's characteristics and network's growth on prices.

Third, we show that the position of an agent in a network has an important influence on her persistence in the market. A larger number of direct links improves the probability to sustain market presence. This result is in line with the findings in the entrepreneurship literature, where evidence on the importance of formal and informal networks for the survival of start-ups was provided (Brüderl and Preisendörfer, 1998; Hoang and Antoncic, 2003; Raz and Gloor, 2007). It is also consistent with anecdotal evidence, where dealers report that their connections to other actors in the art market provide them with key information on market conditions including prices, client demand, new sources of supply, and changes in the competitive landscape. This information tends to be more valuable than public information such as auction results.

Lastly, consistent with the structures prevalent in the financial industry (Allen and Gale, 2000; Babus, 2016; Furfine, 2003; Gai and Kapadia, 2010; Lux, 2015), our results show that the art market is characterized by a few central players who nurture the rest of the network. The connectedness within the network is rather low. Dealers are only indirectly connected to each other through common sellers they interact with and those connections are not extensive preventing dissipation of information rents manifested in lower relative prices. This network structure remains persistent over a full century. As outlined in the 2017 Tefaf report (Pownall, 2017), similar structures can still be observed in the art market today. A small number of art dealers dominate the industry in terms of sales, leading to preferential information sharing. However, there are signs that cooperation, especially on the international level, is increasing. While this should result in a denser network, where risks can be shared, it can also raise the potential for contagion.

Exploiting large data sets can yield important insights about the interdependent decision making of linked individuals from which valuable policy implications can be derived. Within the context 
of the art market, driving forces for network formation and resulting structures among dealers may explain price developments for certain artists as well as record prices yielded at auctions. Events like Brexit may dry up the market and make link formation among dealers very costly. On the other hand, it might make the formation of connections particularly beneficial due to the potential for risk sharing.

Additionally, our findings have important policy and governance implications for industries in which high market concentrations prevail. Examples extend from the financial industry and research collaborations to energy providers and car manufacturers. Understanding the formation of and the motivations behind a network-cooperation, risk sharing, or competition-are important to understand industry dynamics and key concerns. Identifying unprofitable structures and closing gaps in networks can result in increased payoffs, reduced fragility, and more transparency. Efforts should be directed toward breaking down deadlocked structures which yield benefits to only a few and create risk for the entire network.

Eventually, regulators need to create incentives for market participants to create socially beneficial networks structures. A resilient and efficient market can exist only with well-balanced connections in complete networks where information can flow freely. This is true for every market and especially for those which impose externalities upon the economy and society as a whole. 


\section{References}

Allen, F. and Gale, D. (2000). Financial contagion. Journal of Political Economy, 108(1):1-33.

Ashenfelter, O. (1989). How auctions work for wine and art. The Journal of Economic Perspectives, $3(3): 23-36$.

Ashenfelter, O. and Graddy, K. (2003). Auctions and the price of art. Journal of Economic Literature, 41(3):763-787.

Ashenfelter, O. and Graddy, K. (2011). Art auctions. Edward Elgar Publishing, Cheltenham.

Babus, A. (2016). The formation of financial networks. The RAND Journal of Economics, 47(2):239272.

Bala, V. and Goyal, S. (1998). Learning from neighbours. The Review of Economic Studies, 65(3):595-621.

Bala, V. and Goyal, S. (2000). A noncooperative model of network formation. Econometrica, 68(5):1181-1229.

Bayer, T. M. (2015). The Development of the Art Market in England: Money as Muse, 1730-1900. Routledge.

Brüderl, J. and Preisendörfer, P. (1998). Network support and the success of newly founded business. Small Business Economics, 10(3):213-225.

Chanel, O., Gerard-Varet, L.-A., et al. (1996). Auction theory and practice evidence from the market for jewellery. Technical report, Universite Aix-Marseille III.

Christakis, N. A., Fowler, J. H., Imbens, G. W., and Kalyanaraman, K. (2010). An empirical model for strategic network formation. Technical report, National Bureau of Economic Research.

Cocco, J. F., Gomes, F. J., and Martins, N. C. (2009). Lending relationships in the interbank market. Journal of Financial Intermediation, 18(1):24-48.

Colla, P. and Mele, A. (2010). Information linkages and correlated trading. Review of Financial Studies, 23(1):203-246.

Cooper, J. (1977). Under the hammer: the auctions and auctioneers of London. Constable \& Company Limited.

Corominas-Bosch, M. (2004). Bargaining in a network of buyers and sellers. Journal of Economic Theory, 115(1):35-77.

Currarini, S., Jackson, M. O., and Pin, P. (2009). An economic model of friendship: Homophily, minorities, and segregation. Econometrica, 77(4):1003-1045. 
De Silva, D. G., Gertsberg, M., and Pownall, R. A. (2016). Market evolution, bidding strategies, and survival of art dealers. Available at SSRN: http://ssrn.com/abstract=2866949.

De Silva, D. G., Kosmopoulou, G., and Lamarche, C. (2009). The effect of information on the bidding and survival of entrants in procurement auctions. Journal of Public Economics, 93(1):56-72.

Deltas, G. and Kosmopoulou, G. (2004). 'catalogue'vs 'order-of-sale'effects in sequential auctions: theory and evidence from a rare book sale. The Economic Journal, 114(492):28-54.

Dubini, P. and Aldrich, H. (1991). Personal and extended networks are central to the entrepreneurial process. Journal of Business Venturing, 6(5):305-313.

Engelbrecht-Wiggans, R., Milgrom, P. R., and Weber, R. J. (1983). Competitive bidding and proprietary information. Journal of Mathematical Economics, 11(2):161-169.

Furfine, C. (2003). Interbank exposures: Quantifying the risk of contagion. Journal of Money, Credit, and Banking, 35(1):111-128.

Gai, P. and Kapadia, S. (2010). Contagion in financial networks. Bank of England Working Papers 383, Bank of England.

Ginsburgh, V. (1998). Absentee bidders and the declining price anomaly in wine auctions. Journal of Political Economy, 106(6):1302-1319.

Ginsburgh, V. and van Ours, J. C. (2007). On organizing a sequential auction: results from a natural experiment by christie's. Oxford Economic Papers, 59(1):1-15.

Goyal, S. (2012). Connections: an introduction to the economics of networks. Princeton University Press.

Graves, A. (1918). Art sales from early in the eighteenth century to early in the twentieth century, volume 1-3. G, Algernon Graves.

Hendricks, K., Pinkse, J., and Porter, R. H. (2003). Empirical implications of equilibrium bidding in first-price, symmetric, common value auctions. The Review of Economic Studies, 70(1):115-145.

Hendricks, K. and Porter, R. H. (1988). An empirical study of an auction with asymmetric information. The American Economic Review, 78(5):865-883.

Hoang, H. and Antoncic, B. (2003). Network-based research in entrepreneurship: A critical review. Journal of Business Venturing, 18(2):165-187.

Hodgson, D. J. and Vorkink, K. P. (2004). Asset pricing theory and the valuation of canadian paintings. Canadian Journal of Economics/Revue Canadienne d'Économique, 37(3):629-655.

Hong, H. and Shum, M. (2003). Econometric models of asymmetric ascending auctions. Journal of Econometrics, 112(2):327-358. 
Iori, G., Mantegna, R. N., Marotta, L., Miccichè, S., Porter, J., and Tumminello, M. (2015). Networked relationships in the e-mid interbank market: A trading model with memory. Journal of Economic Dynamics and Control, 50:98-116.

Jackson, M. O. (2010). Social and economic networks. Princeton university press.

Jackson, M. O. and Wolinsky, A. (1996). A strategic model of social and economic networks. Journal of Economic Theory, 71(1):44-74.

Karlan, D., Mobius, M., Rosenblat, T., and Szeidl, A. (2009). Trust and social collateral. The Quarterly Journal of Economics, 124(3):1307-1361.

Kenett, D. Y. and Havlin, S. (2015). Network science: a useful tool in economics and finance. Mind \& Society, 14(2):155-167.

Kranton, R. E. and Minehart, D. F. (2000). Networks versus vertical integration. The RAND Journal of Economics, 31(3):570-601.

Kranton, R. E. and Minehart, D. F. (2001). A theory of buyer-seller networks. American Economic Review, 91(3):485 - 508.

Li, T. and Zheng, X. (2009). Entry and competition effects in first-price auctions: theory and evidence from procurement auctions. The Review of Economic Studies, 76(4):1397-1429.

Lux, T. (2015). Emergence of a core-periphery structure in a simple dynamic model of the interbank market. Journal of Economic Dynamics and Control, 52:A11-A23.

McPherson, M., Smith-Lovin, L., and Cook, J. M. (2001). Birds of a feather: Homophily in social networks. Annual Review of Sociology, 27(1):415-444.

Milgrom, P. R. and Weber, R. J. (1982). A theory of auctions and competitive bidding. Econometrica: Journal of the Econometric Society, 50(5):1089-1122.

Ozsoylev, H. N. and Walden, J. (2011). Asset pricing in large information networks. Journal of Economic Theory, 146(6):2252-2280.

Ozsoylev, H. N., Walden, J., Yavuz, M. D., and Bildik, R. (2014). Investor networks in the stock market. Review of Financial Studies, 27(5):1323-1366.

Pesando, J. and Shum, P. M. (1996). Price anomalies at auction: Evidence from the market for modern prints. Contributions to Economic Analysis, 237:113-134.

Pownall, R. A. J. (2017). TEFAF Art Market Report 2017. European Fine Art Foundation.

Raz, O. and Gloor, P. A. (2007). Size really matters - new insights for start-ups'survival. Management Science, 53(2):169-177.

Rosen, S. (1974). Hedonic prices and implicit markets: product differentiation in pure competition. The Journal of Political Economy, 82(1):34-55. 
Uzzi, B. (1996). The sources and consequences of embeddedness for the economic performance of organizations: The network effect. American Sociological Review, 61(4):674-698.

Velthuis, O. (2013). Talking Prices: Symbolic Meanings of Prices on the Market for Contemporary Art: Symbolic Meanings of Prices on the Market for Contemporary Art. Princeton University Press.

Wasserman, S. and Faust, K. (1994). Social network analysis: Methods and applications, volume 8. Cambridge University Press.

Wilson, R. (1998). Sequential equilibria of asymmetric ascending auctions: The case of log-normal distributions. Economic Theory, 12(2):433-440. 


\section{Figures}

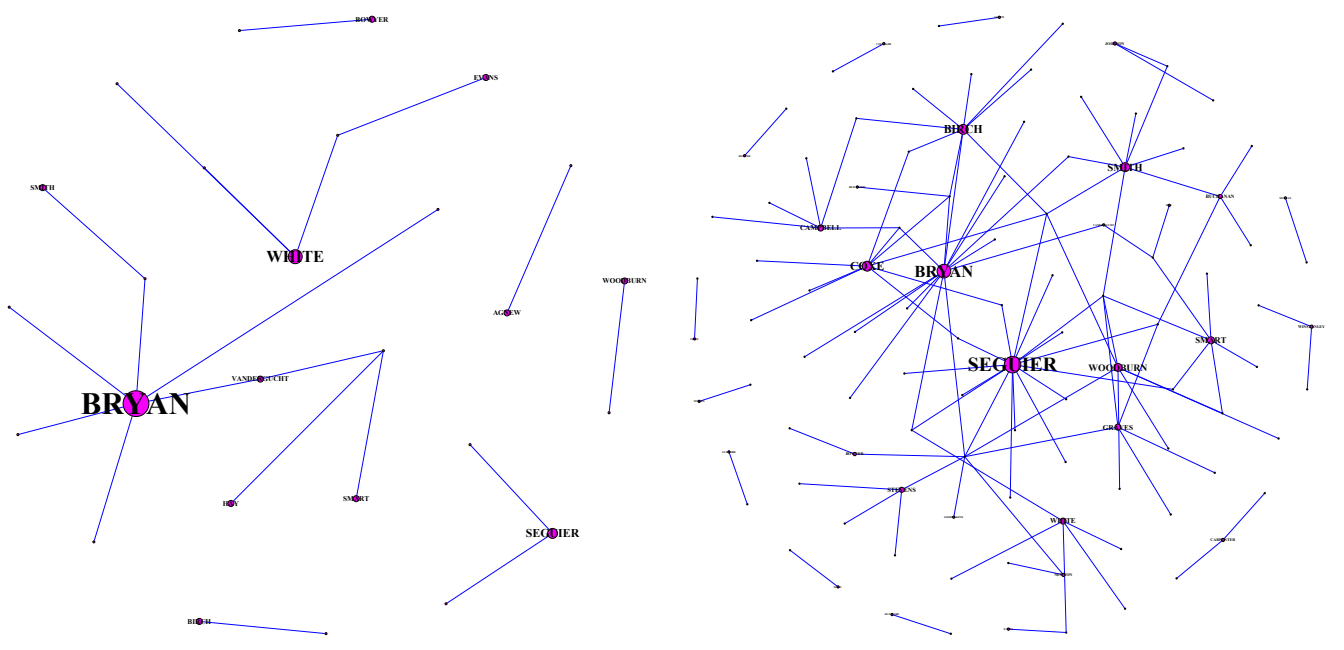

(a) Network in 1800

(b) Network in 1820
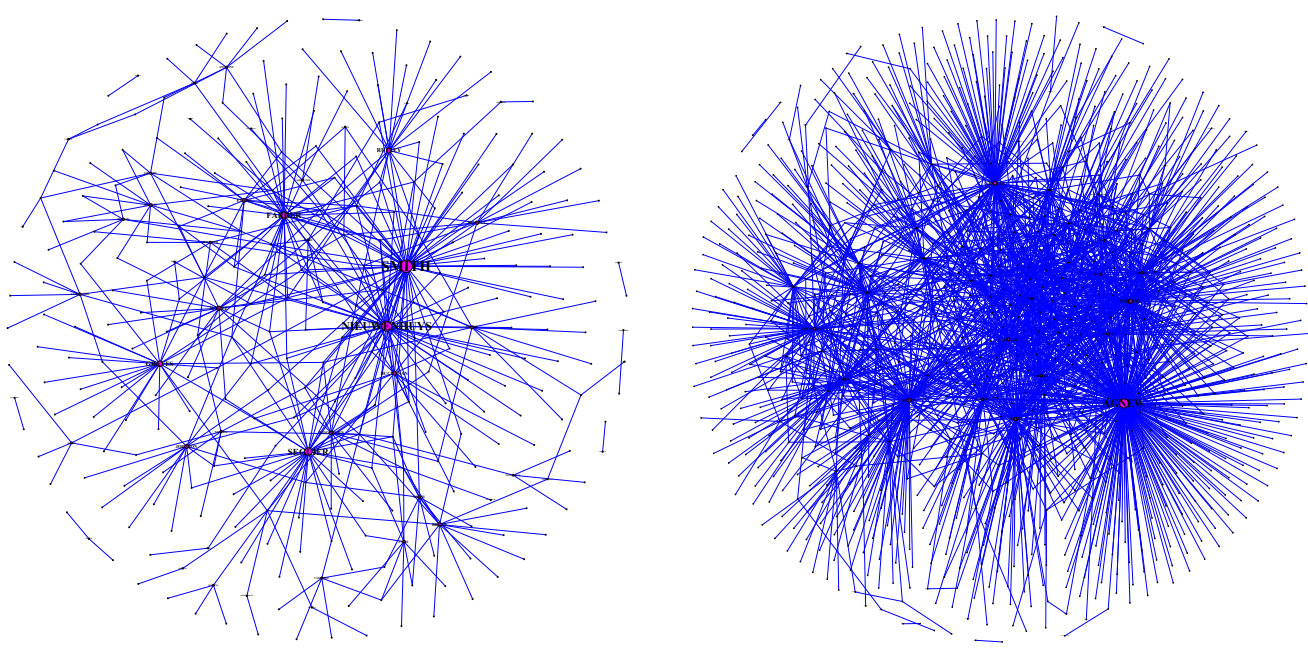

(c) Network in 1850

(d) Network in 1880

Figure 1: Network Evolution (1800-1880) 


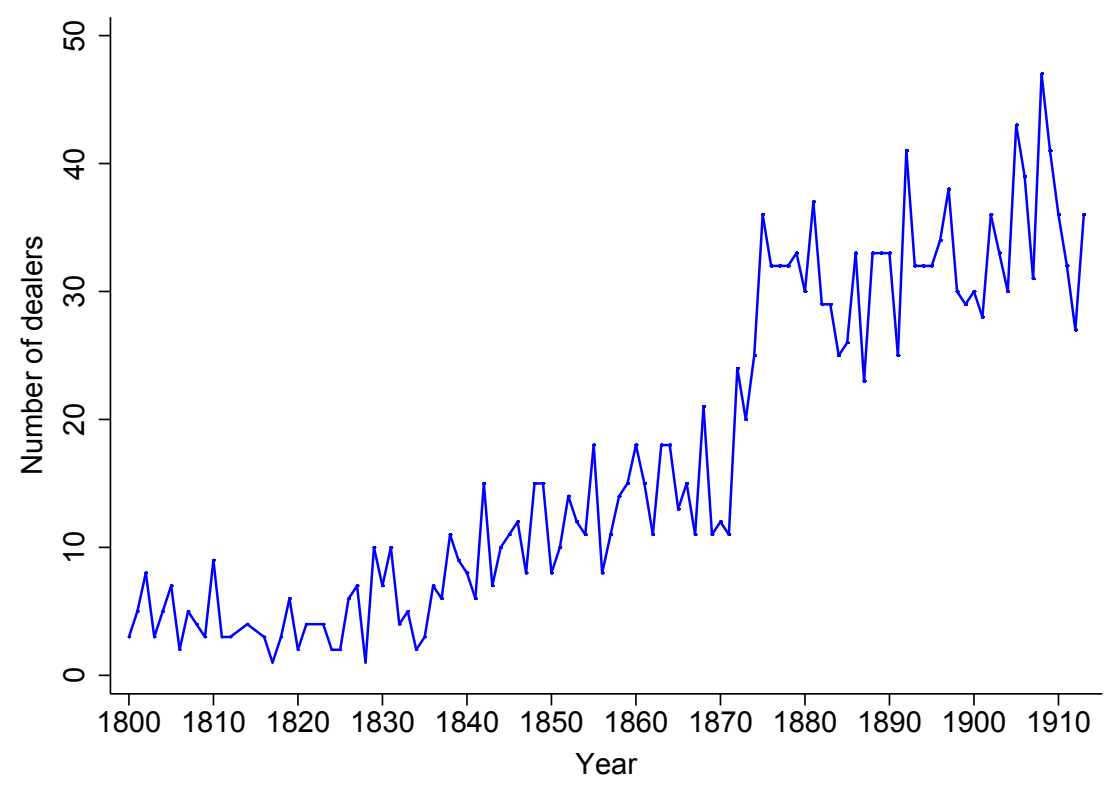

(a) Number of dealers over time

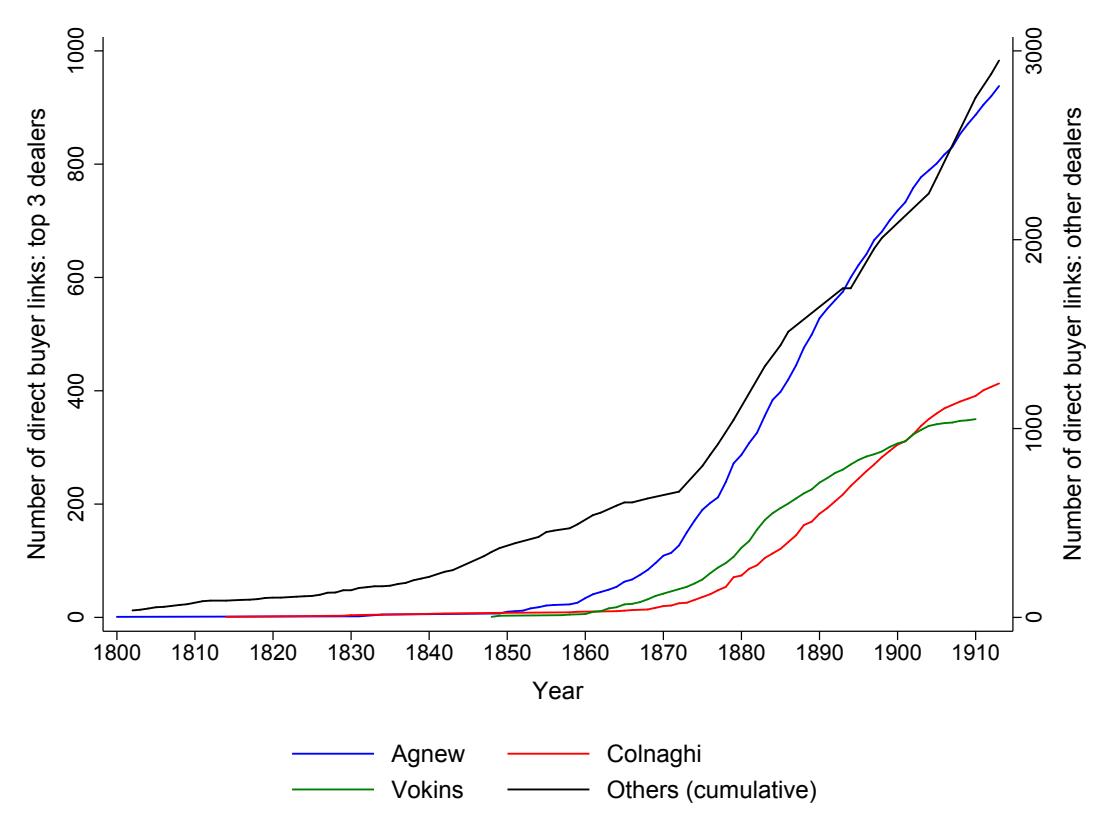

(b) Number of direct links over time

Figure 2: Evolution of dealers' network over time 


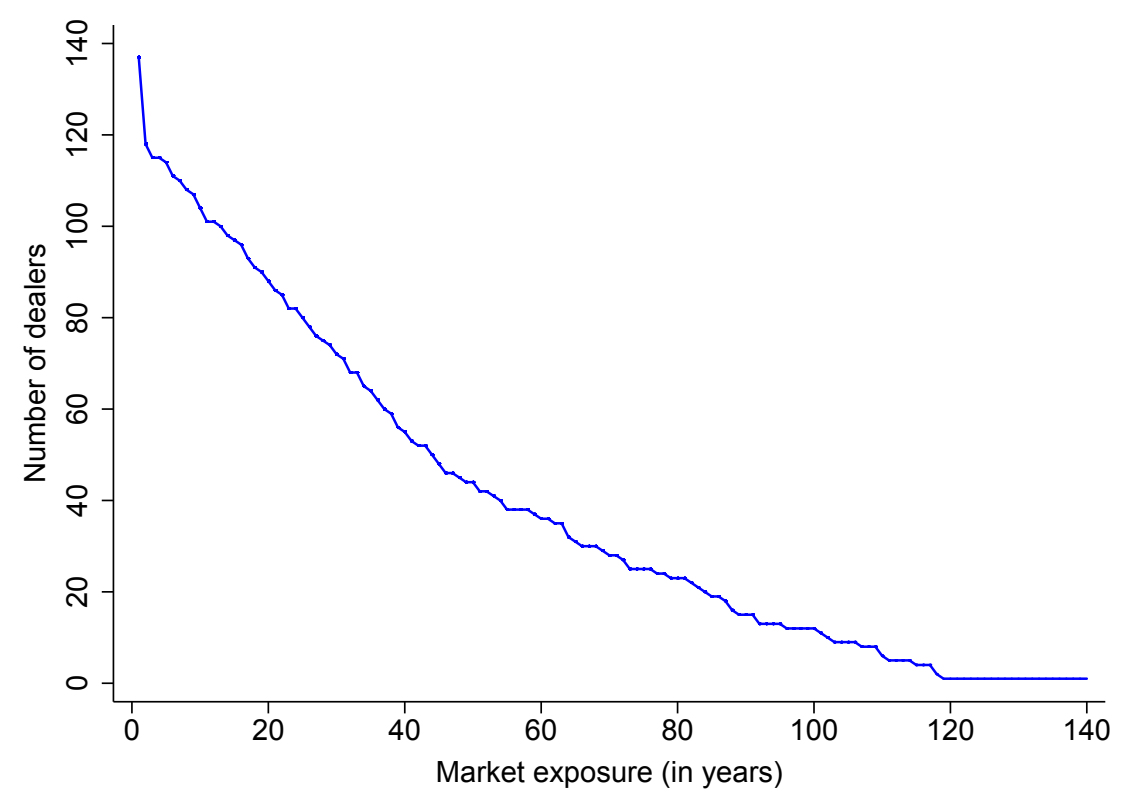

(a) Number of dealers by years of market exposure

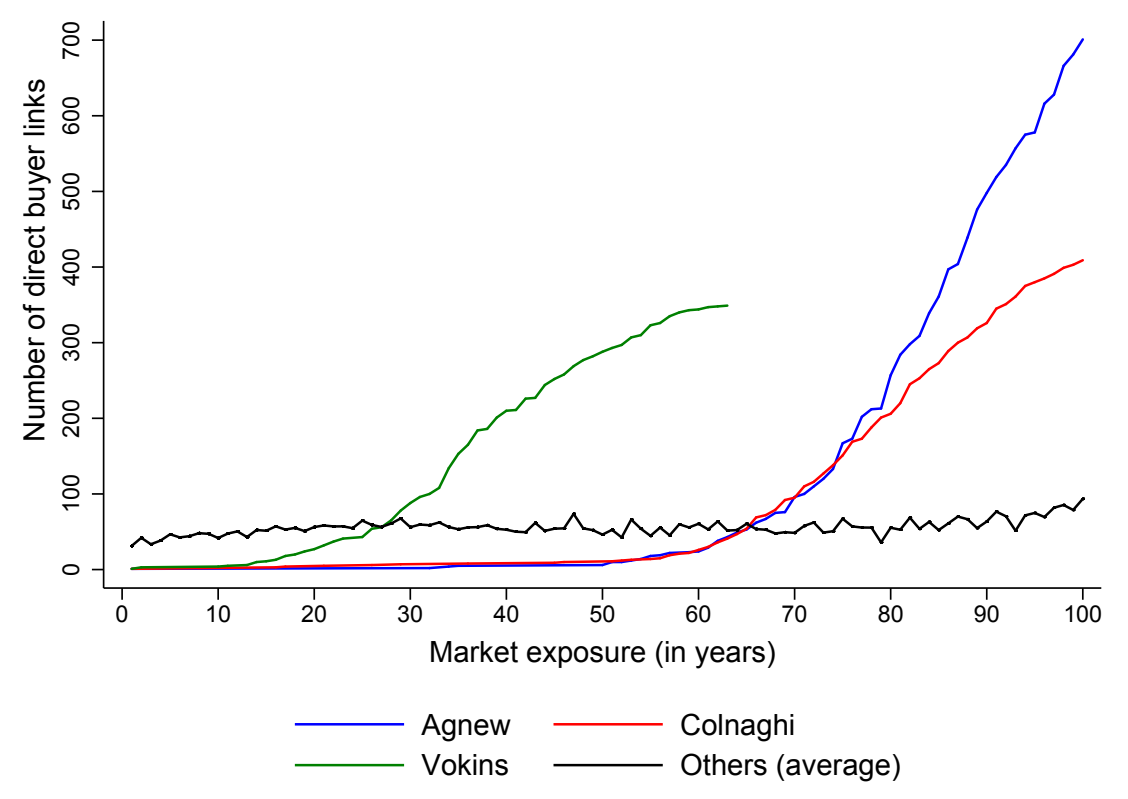

(b) Number of direct links by years of market exposure

Figure 3: Evolution of dealers' network by years of market exposure 


\section{COLNAGHI}

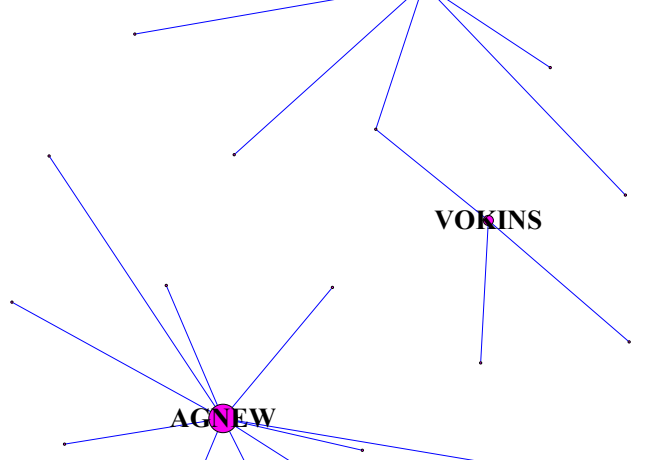

(a) Network in 1850

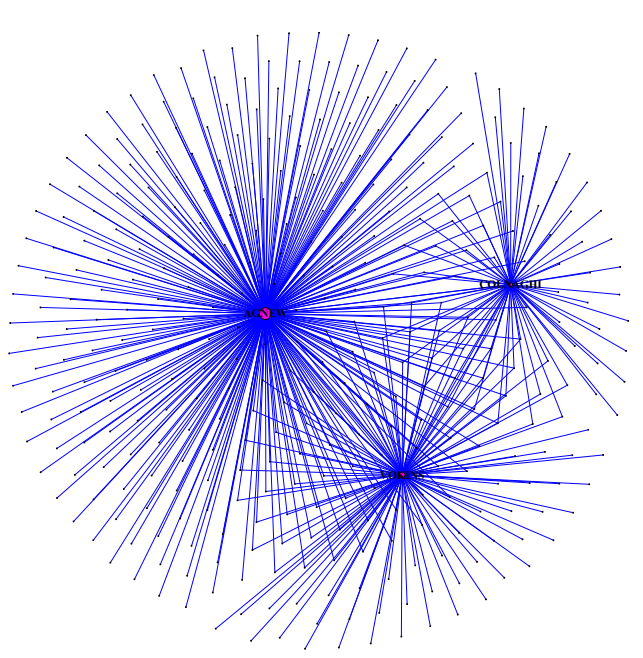

(b) Network in 1880

Figure 4: Networks of Agnew, Colnaghi, and Vokins in 1850 and 1880 


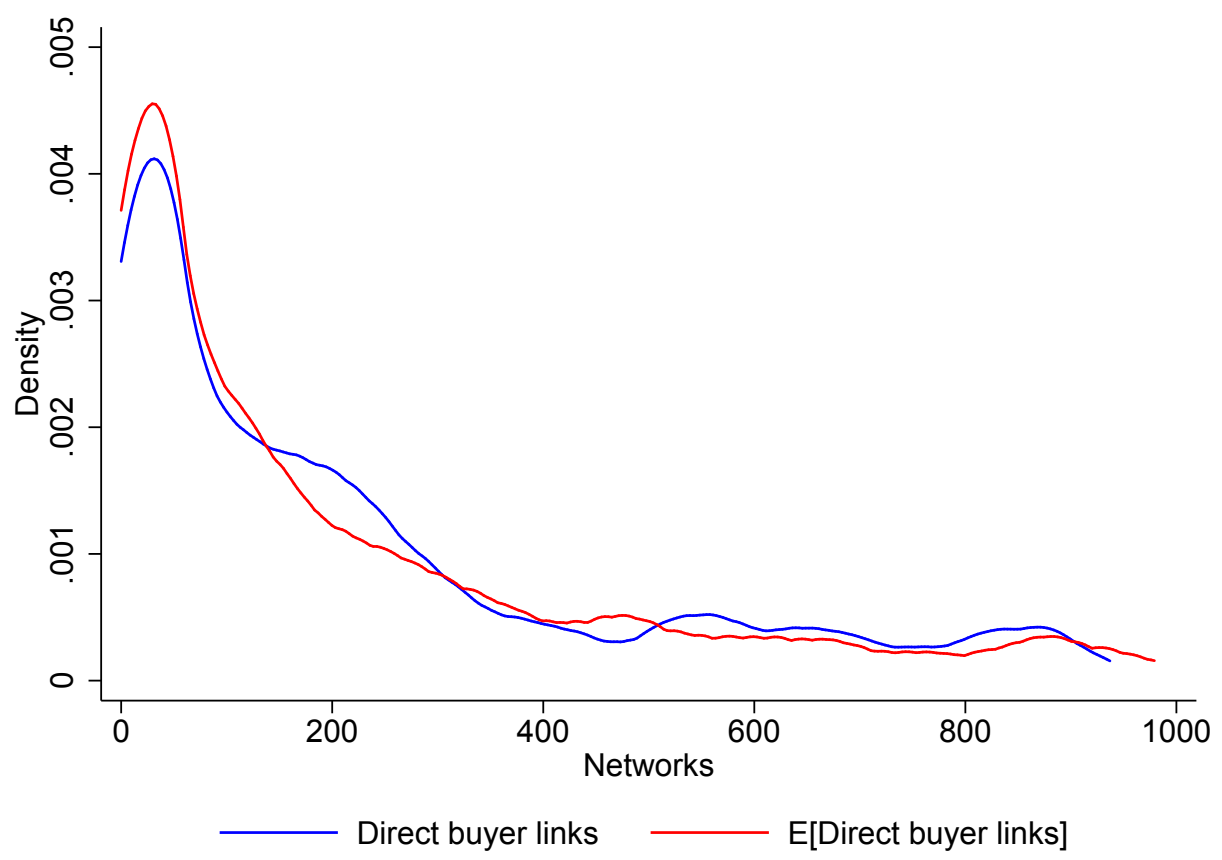

Figure 5: Predicted number of direct buyer links versus actual number of direct buyer links 


\section{Tables}

Table 1: Top 25 dealers with averages of key variables

\begin{tabular}{|c|c|c|c|c|c|}
\hline Rank & Dealer & $\begin{array}{r}\text { Total number of } \\
\text { transactions }\end{array}$ & $\begin{array}{r}\text { Total value of } \\
\text { transactions }\end{array}$ & $\begin{array}{r}\text { Total number of } \\
\text { direct links }\end{array}$ & $\begin{array}{l}\text { Average number of } \\
\text { same-pair transactions }\end{array}$ \\
\hline 1 & Agnew & 4988 & $2,623,168.00$ & 938 & 5.31 \\
\hline 2 & Vokins & 910 & $274,028.40$ & 350 & 2.61 \\
\hline 3 & Colnaghi & 862 & $394,088.70$ & 413 & 2.08 \\
\hline 4 & Tooth & 743 & $274,173.00$ & 336 & 2.21 \\
\hline 5 & Wallis & 670 & $255,554.70$ & 276 & 2.41 \\
\hline 6 & McLean & 609 & $151,368.40$ & 299 & 2.03 \\
\hline 7 & Gooden \& Fox & 476 & $178,666.00$ & 211 & 2.26 \\
\hline 8 & Permain & 359 & $75,838.34$ & 191 & 1.88 \\
\hline 9 & Smith & 284 & $62,028.69$ & 161 & 1.77 \\
\hline 10 & Lesser & 245 & $64,805.10$ & 174 & 1.40 \\
\hline 11 & White & 230 & $55,267.03$ & 136 & 1.70 \\
\hline 12 & Graves & 229 & $38,946.65$ & 139 & 1.65 \\
\hline 13 & Wertheimer & 221 & $239,346.50$ & 126 & 1.75 \\
\hline 14 & Sampson & 215 & $47,286.80$ & 125 & 1.72 \\
\hline 15 & Leggatt & 145 & $23,253.23$ & 101 & 1.44 \\
\hline 16 & Polak & 141 & $18,176.68$ & 109 & 1.29 \\
\hline 17 & Shepherd & 139 & $25,240.32$ & 105 & 1.32 \\
\hline 18 & Lawrie & 122 & $71,849.11$ & 66 & 1.85 \\
\hline 19 & Nieuwenhuys & 118 & $33,451.45$ & 67 & 1.76 \\
\hline 20 & Gambart & 114 & $23,599.48$ & 52 & 2.24 \\
\hline 21 & Grindley & 112 & $15,797.36$ & 66 & 1.70 \\
\hline 22 & Sedelmeyer & 107 & $47,850.61$ & 46 & 2.33 \\
\hline 23 & Pilgram \& Lefevre & 103 & $40,967.01$ & 44 & 2.34 \\
\hline 24 & Rutley & 100 & $14,279.97$ & 65 & 1.54 \\
\hline 25 & Col & 100 & $18,756.38$ & 42 & 2.38 \\
\hline $26-137$ & Others & 2,407 & $839,861.98$ & $13.88^{*}$ & 1.62 \\
\hline
\end{tabular}

All prices are in constant $£ 1900$ and were converted using the UK CPI provided by the Bank of England.

*Average across all other dealers. 


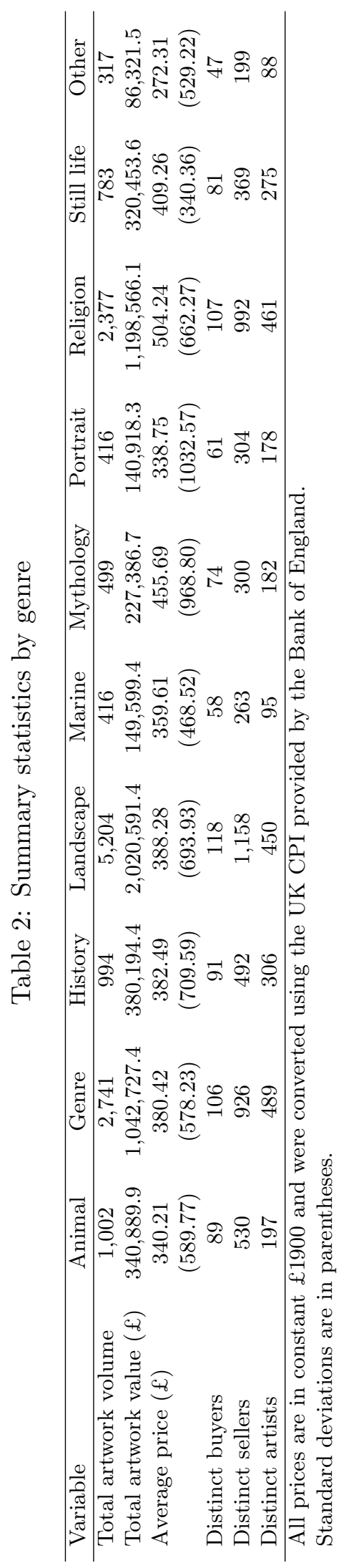


Table 3: Summary statistics for buyer and seller specialization by genre

\begin{tabular}{lcc}
\hline Variable & Average specialization buyer & Average specialization seller \\
\hline Animal & 0.065 & 0.063 \\
& $(0.083)$ & $(0.083)$ \\
Genre & 0.191 & 0.194 \\
History & $(0.111)$ & $(0.119)$ \\
& 0.069 & 0.062 \\
Landscape & $(0.094)$ & $(0.091)$ \\
& 0.349 & 0.369 \\
Marine & $(0.171)$ & $(0.171)$ \\
& 0.031 & 0.030 \\
Mythology & $(0.050)$ & $(0.047)$ \\
& 0.040 & 0.038 \\
Portrait & $(0.059)$ & $(0.062)$ \\
& 0.146 & 0.142 \\
Religion & $(0.150)$ & $(0.151)$ \\
& 0.056 & 0.051 \\
Still life & $(0.085)$ & $(0.084)$ \\
& 0.024 & 0.020 \\
Other & $(0.049)$ & $(0.042)$ \\
& 0.033 & 0.031 \\
& $(0.052)$ & $(0.054)$ \\
\hline
\end{tabular}

Standard deviations are in parentheses.

Table 4: Summary statistics network formation

\begin{tabular}{lcc}
\hline Variable & Mean & Sd \\
\hline Probability of forming a direct buyer link & 0.049 & 0.215 \\
Past number of direct buyer links & 33.550 & 78.264 \\
Past number of direct buyer links with 10 year moving window & 14.895 & 33.627 \\
Past number of same-pair transactions & 0.036 & 0.709 \\
Past number of common connections & 0.012 & 0.141 \\
Buyer's market exposure (in years) & 38.221 & 29.308 \\
Past capacity seller (in £) & $1,736.123$ & $6,953.613$ \\
Past homophily & 0.625 & 0.330 \\
Past genre specialization buyer-seller: absolute difference & 0.338 & 0.264 \\
\hline
\end{tabular}

Seller capacity is in constant $£ 1900$. 


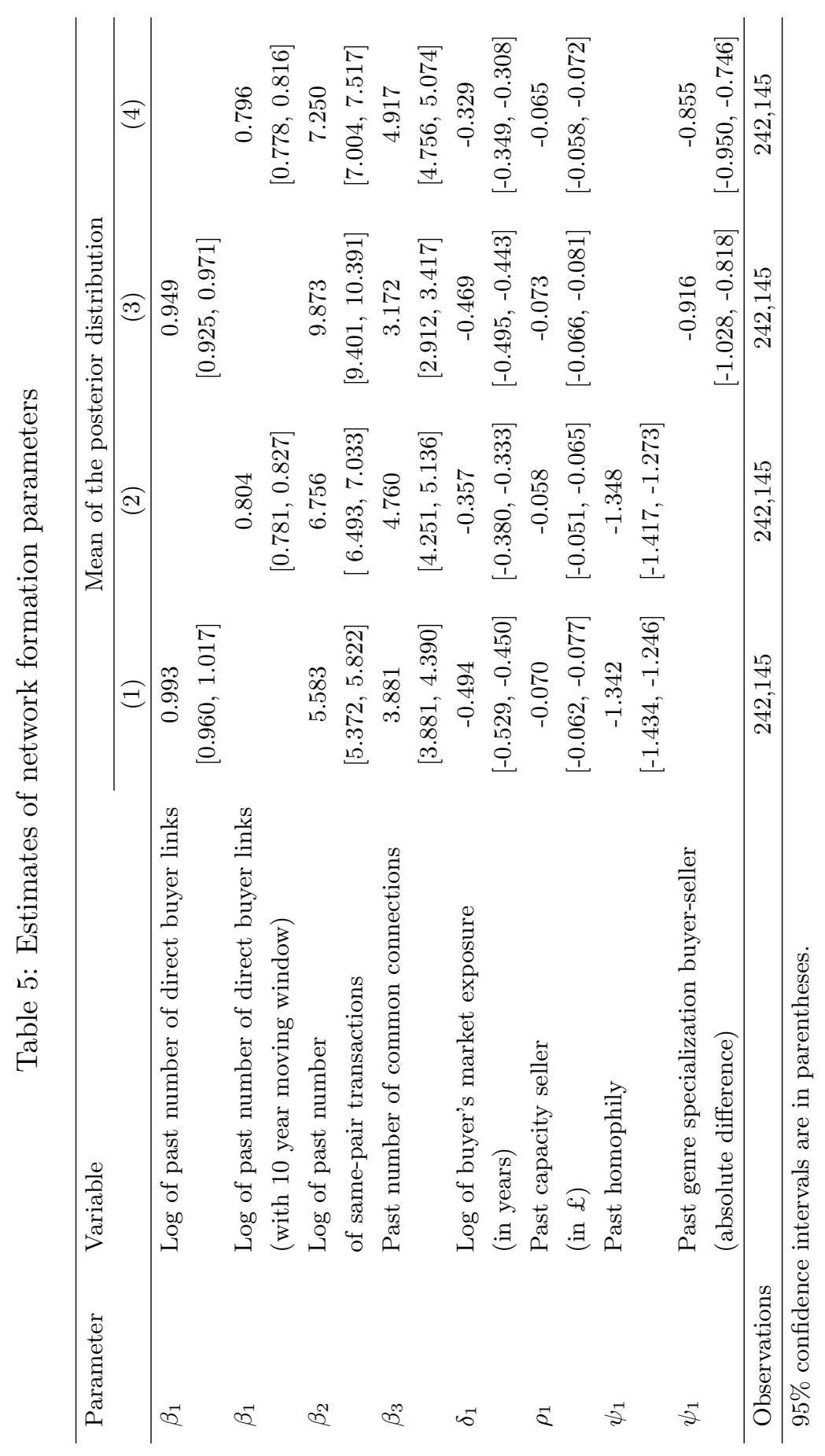


Table 6: Summary statistics network effects on price

\begin{tabular}{lcc}
\hline Variable & Mean & Sd \\
\hline Price (in £) & 446.397 & 786.017 \\
Past number of direct buyer links & 226.826 & 247.583 \\
Past number of direct buyer links with 10 year moving window & 94.218 & 105.383 \\
Past number of same-pair transactions & 1.000 & 5.015 \\
Past number of common connections & 0.123 & 0.384 \\
Buyer's market exposure (in years) & 60.837 & 32.903 \\
Past genre specialization buyer: buyer-seller & -0.072 & 0.236 \\
Past capacity seller (£) & $2,603.326$ & $8,149.814$ \\
Number of bidders & 11.238 & 7.324 \\
Expected number of bidders & 8.248 & 5.996 \\
Average lot sequence in auction sale & 16.871 & 16.723 \\
Past rival's maximum capacity (in £) & $1,135.040$ & $4,766.622$ \\
Past rival's maximum share by volume & 0.028 & 0.094 \\
\hline Seller capacity is in constant $£ 1900$. & &
\end{tabular}

Seller capacity is in constant $£ 1900$. 
Table 7: Network effects on prices

\begin{tabular}{|c|c|c|c|c|c|c|}
\hline \multirow[t]{2}{*}{ Variable } & \multicolumn{6}{|c|}{$\log ($ price $)$} \\
\hline & (1) & (2) & (3) & (4) & (5) & (6) \\
\hline $\begin{array}{l}\text { Log of past number of distinct networks } \\
\text { by buyer }\end{array}$ & $\begin{array}{c}-0.156^{* * *} \\
(0.022)\end{array}$ & $\begin{array}{c}-0.160^{* * *} \\
(0.022)\end{array}$ & $\begin{array}{c}-0.164^{* * *} \\
(0.022)\end{array}$ & & & \\
\hline $\begin{array}{l}\text { Log of past number of distinct networks } \\
\text { by buyer with } 10 \text { year moving window }\end{array}$ & & & & $\begin{array}{c}-0.176^{* * *} \\
(0.021)\end{array}$ & $\begin{array}{c}-0.182^{* * *} \\
(0.021)\end{array}$ & $\begin{array}{c}-0.182^{* * *} \\
(0.021)\end{array}$ \\
\hline $\begin{array}{l}\text { Log of number of transactions } \\
\text { by same buyer and seller }\end{array}$ & $\begin{array}{c}-0.093^{* * *} \\
(0.021)\end{array}$ & $\begin{array}{c}-0.096^{* * *} \\
(0.021)\end{array}$ & $\begin{array}{c}-0.089^{* * *} \\
(0.021)\end{array}$ & $\begin{array}{c}-0.090^{* * *} \\
(0.021)\end{array}$ & $\begin{array}{c}-0.093^{* * *} \\
(0.021)\end{array}$ & $\begin{array}{c}-0.087^{* * *} \\
(0.021)\end{array}$ \\
\hline Past number of common networks & $\begin{array}{l}0.046 \\
(0.033)\end{array}$ & $\begin{array}{c}0.050 \\
(0.033)\end{array}$ & $\begin{array}{c}0.046 \\
(0.033)\end{array}$ & $\begin{array}{c}0.046 \\
(0.033)\end{array}$ & $\begin{array}{c}0.049 \\
(0.033)\end{array}$ & $\begin{array}{c}0.046 \\
(0.033)\end{array}$ \\
\hline Log of buyer's market exposure (in years) & $\begin{array}{c}0.223^{* * *} \\
(0.028)\end{array}$ & $\begin{array}{c}0.223^{* * *} \\
(0.028)\end{array}$ & $\begin{array}{c}0.223^{* * *} \\
(0.028)\end{array}$ & $\begin{array}{c}0.187^{* * *} \\
(0.027)\end{array}$ & $\begin{array}{c}0.185^{* * *} \\
(0.027)\end{array}$ & $\begin{array}{c}0.185^{* * *} \\
(0.027)\end{array}$ \\
\hline $\begin{array}{l}\text { Object specific specialization difference: } \\
\text { buyer - seller }\end{array}$ & $\begin{array}{l}-0.064^{*} \\
(0.038)\end{array}$ & $\begin{array}{l}-0.037 \\
(0.038)\end{array}$ & $\begin{array}{c}-0.093^{* *} \\
(0.038)\end{array}$ & $\begin{array}{l}-0.065^{*} \\
(0.038)\end{array}$ & $\begin{array}{l}-0.032 \\
(0.038)\end{array}$ & $\begin{array}{c}-0.093^{* *} \\
(0.038)\end{array}$ \\
\hline Log of past capacity of seller & $\begin{array}{c}0.003 \\
(0.003)\end{array}$ & $\begin{array}{c}0.003 \\
(0.003)\end{array}$ & $\begin{array}{c}0.002 \\
(0.003)\end{array}$ & $\begin{array}{c}0.003 \\
(0.003)\end{array}$ & $\begin{array}{c}0.003 \\
(0.003)\end{array}$ & $\begin{array}{c}0.002 \\
(0.003)\end{array}$ \\
\hline Log number of bidders & $\begin{array}{c}0.041^{* * *} \\
(0.015)\end{array}$ & $\begin{array}{c}0.039^{* *} \\
(0.015)\end{array}$ & & $\begin{array}{c}0.041^{* * *} \\
(0.015)\end{array}$ & $\begin{array}{c}0.041^{* * *} \\
(0.015)\end{array}$ & \\
\hline Log of expected number of bidders & & & $\begin{array}{c}0.121^{* * *} \\
(0.013)\end{array}$ & & & $\begin{array}{c}0.117^{* * *} \\
(0.013)\end{array}$ \\
\hline Log of lot sequence & $\begin{array}{c}0.156^{* * *} \\
(0.009)\end{array}$ & $\begin{array}{c}0.154^{* * *} \\
(0.010)\end{array}$ & $\begin{array}{c}0.108^{* * *} \\
(0.010)\end{array}$ & $\begin{array}{c}0.157^{* * *} \\
(0.009)\end{array}$ & $\begin{array}{c}0.157^{* * *} \\
(0.010)\end{array}$ & $\begin{array}{c}0.111^{* * *} \\
(0.010)\end{array}$ \\
\hline $\begin{array}{l}\text { Log of rivals' average past number } \\
\text { of distinct networks }\end{array}$ & & $\begin{array}{c}0.021^{* * *} \\
(0.008)\end{array}$ & & & $\begin{array}{c}0.013 \\
(0.009)\end{array}$ & \\
\hline Log of rivals' past maximum capacity & $\begin{array}{c}0.029 * * * \\
(0.004)\end{array}$ & & $\begin{array}{c}0.022^{* * *} \\
(0.004)\end{array}$ & $\begin{array}{c}0.028^{* * *} \\
(0.004)\end{array}$ & & $\begin{array}{c}0.022^{* * *} \\
(0.004)\end{array}$ \\
\hline Rivals' past maximum share by volume & $\begin{array}{l}-0.029 \\
(0.092)\end{array}$ & & $\begin{array}{c}0.080 \\
(0.092)\end{array}$ & $\begin{array}{l}-0.029 \\
(0.092)\end{array}$ & & $\begin{array}{c}0.075 \\
(0.092)\end{array}$ \\
\hline Artist alive & $\begin{array}{c}0.165^{* * *} \\
(0.029)\end{array}$ & $\begin{array}{c}0.167^{* * *} \\
(0.029)\end{array}$ & $\begin{array}{c}0.156^{* * *} \\
(0.029)\end{array}$ & $\begin{array}{c}0.165^{* * *} \\
(0.029)\end{array}$ & $\begin{array}{c}0.167^{* * *} \\
(0.029)\end{array}$ & $\begin{array}{c}0.156^{* * *} \\
(0.029)\end{array}$ \\
\hline Buyer effects & Yes & Yes & Yes & Yes & Yes & Yes \\
\hline Year effects & Yes & Yes & Yes & Yes & Yes & Yes \\
\hline Auction house effects & Yes & Yes & Yes & Yes & Yes & Yes \\
\hline Artist effects & Yes & Yes & Yes & Yes & Yes & Yes \\
\hline Medium effects & Yes & Yes & Yes & Yes & Yes & Yes \\
\hline Collection effects & Yes & Yes & Yes & Yes & Yes & Yes \\
\hline Observations & 14,749 & 14,749 & 14,749 & 14,749 & 14,749 & 14,749 \\
\hline R-squared & 0.400 & 0.399 & 0.404 & 0.401 & 0.400 & 0.405 \\
\hline
\end{tabular}

Standard errors are in parentheses. ${ }^{* * *} \mathrm{p}<0.01,{ }^{* *} \mathrm{p}<0.05,{ }^{*} \mathrm{p}<0.1$

Note that, expected numbers of bidders are calculated using estimates from Columns 1 and 2 of Table 5 . 


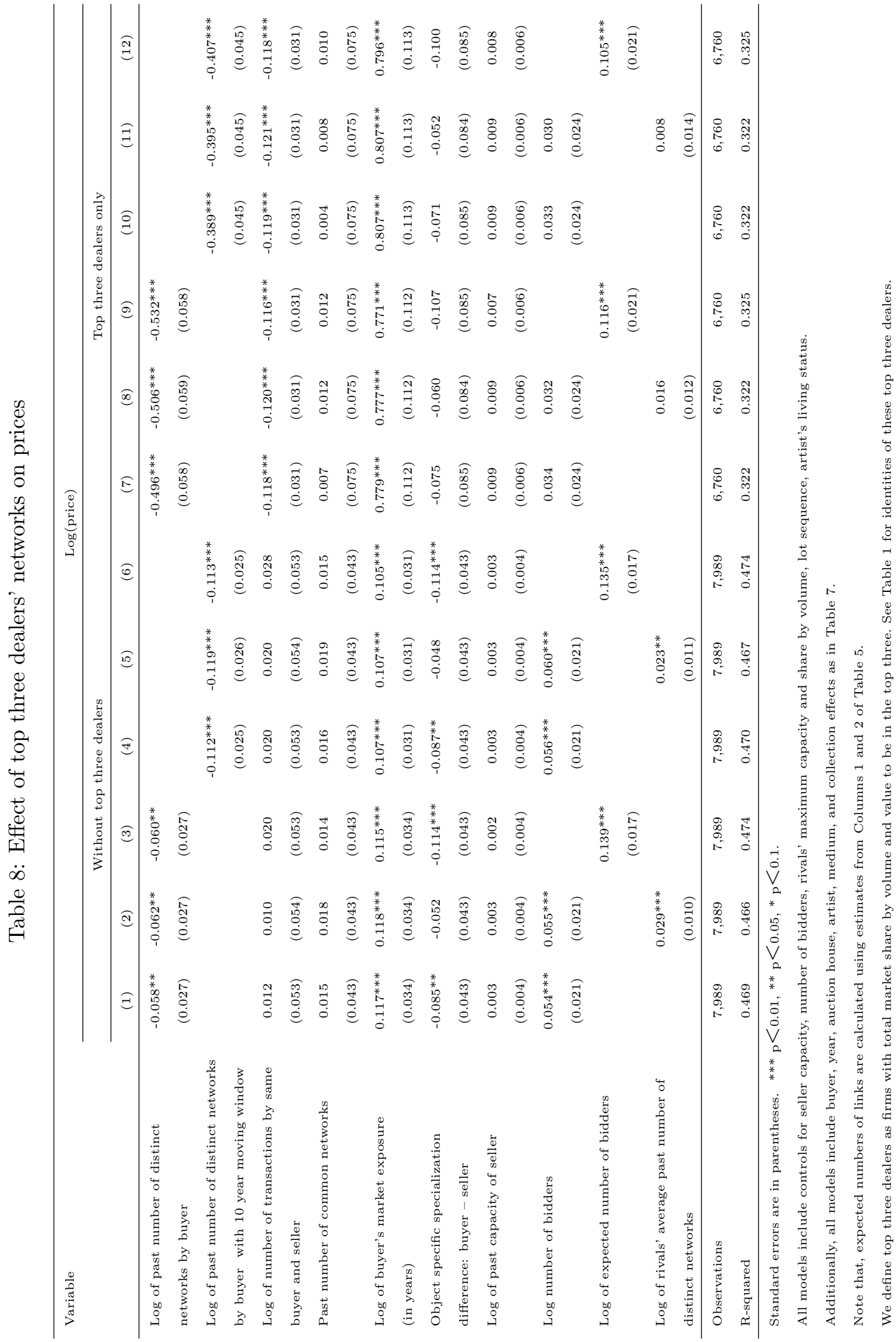


Table 9: Summary statistics for market exit

\begin{tabular}{lcc}
\hline Variable & Mean & $\mathrm{Sd}$ \\
\hline Average past number of direct buyer links (yearly) & 25.402 & 67.775 \\
Average past number of direct buyer links with 10 year moving window (yearly) & 9.442 & 23.498 \\
Buyer's market exposure (in years) & 34.280 & 27.856 \\
Dealer's average share for the last three years (by volume) & 0.024 & 0.052 \\
Dealer's average share for the last three years (by value) $(£)$ & 0.024 & 0.074 \\
Number of rival dealers & 53.748 & 17.596 \\
Number of rivals' networks & 24.965 & 22.097 \\
\hline
\end{tabular}




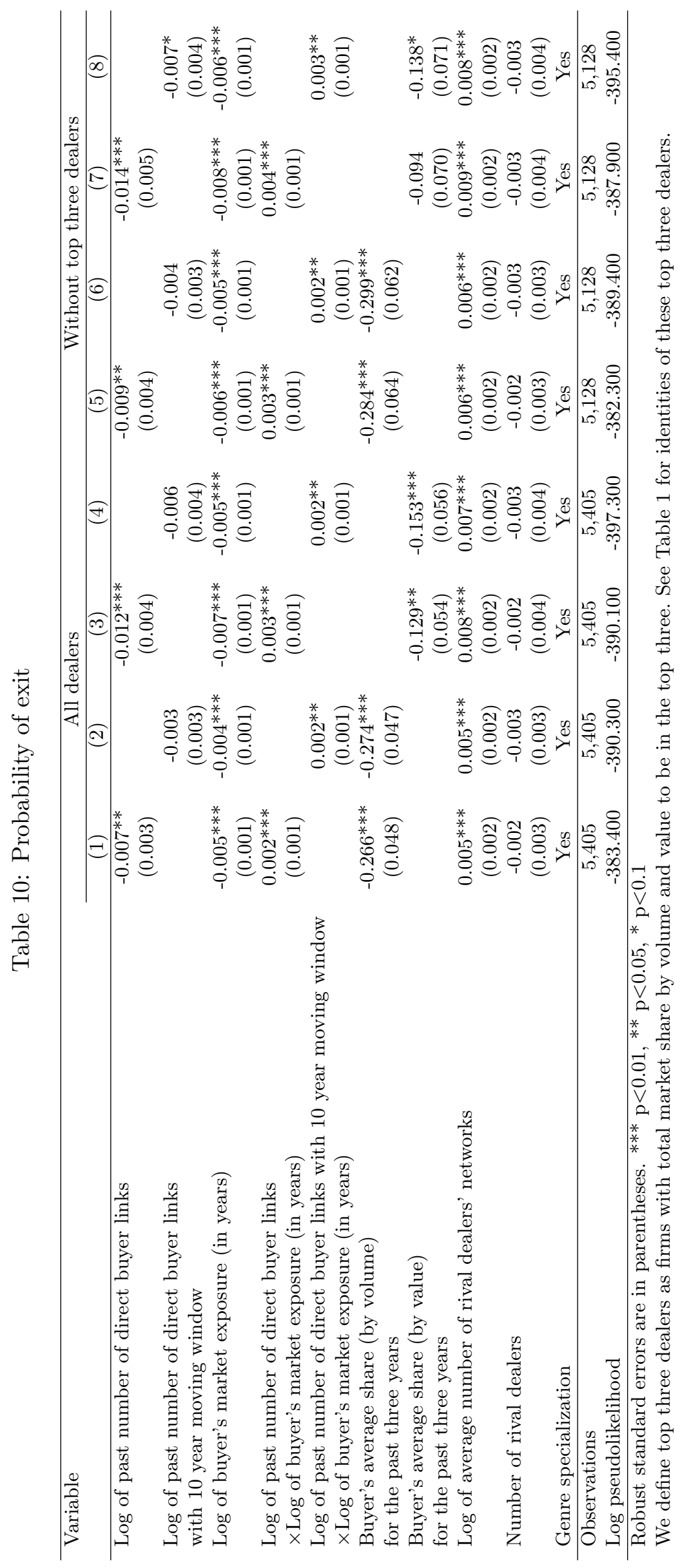




\section{Appendix A}

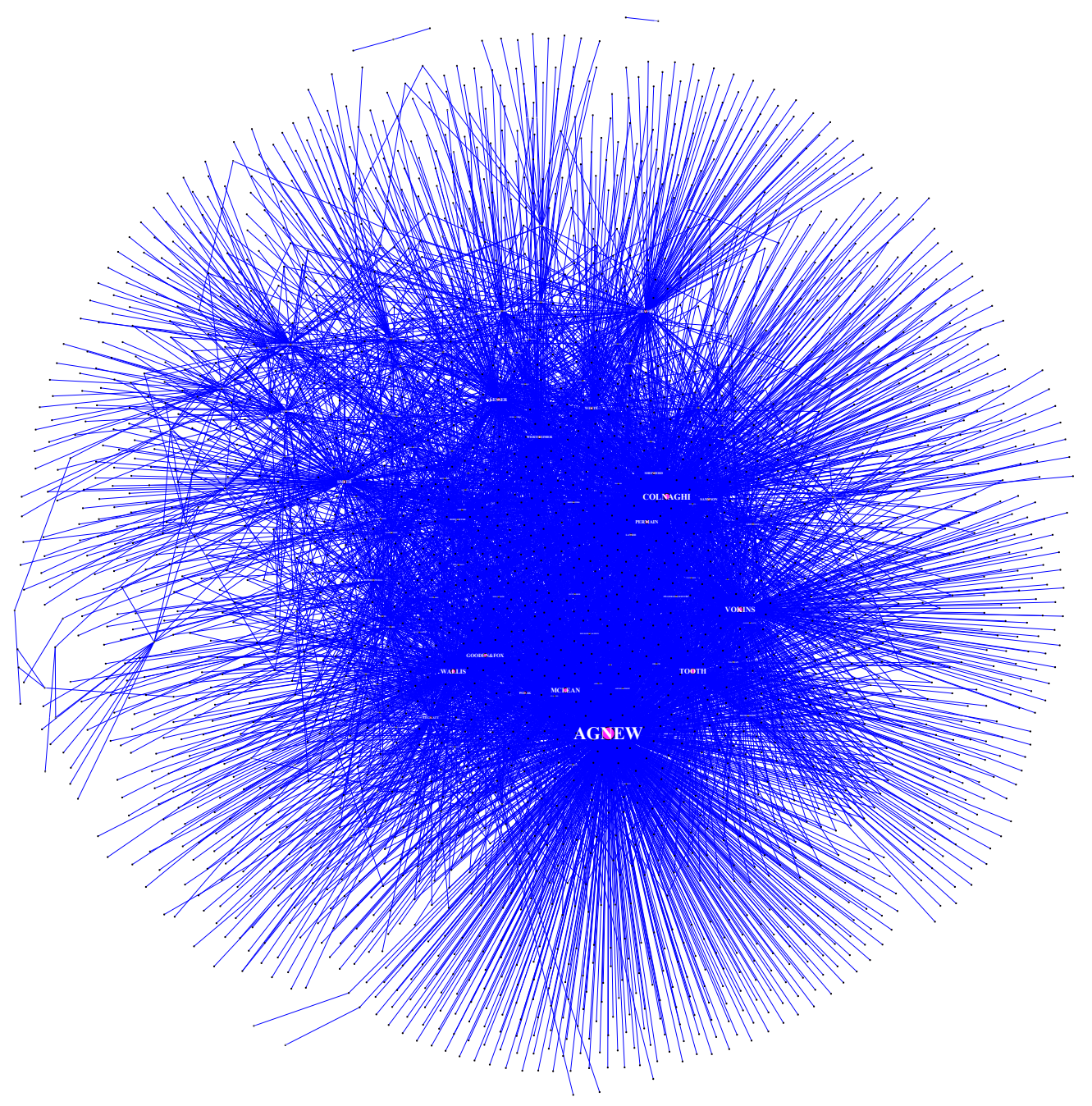

Figure A1: Full network by 1913 


\section{Table A1: Overview of artwork characteristics}

\begin{tabular}{|c|c|}
\hline Variable & Definition/ unit \\
\hline \multicolumn{2}{|c|}{ Personal characteristics of the artist } \\
\hline Name & First and last name of the artist \\
\hline Living status & Dummy indicating if artist was dead or alive at the date of sale \\
\hline Genre & $\begin{array}{l}\text { Indicates to which genre the artwork can be attributed to: animal, } \\
\text { landscape, still life, history, religion, mythology, genre, portrait, marine, other }\end{array}$ \\
\hline Age & Difference between birth year and date of sale \\
\hline \multicolumn{2}{|c|}{ Physical characteristics of the artwork } \\
\hline Size & Height times width in inches \\
\hline Medium & $\begin{array}{l}\text { Dummy indicating if artwork was a painting, sculpture, engraving, } \\
\text { drawing or a copy }\end{array}$ \\
\hline \multicolumn{2}{|c|}{ Transaction characteristics } \\
\hline Sales price & Nominal sales price in Pounds, Sterling and Dimes \\
\hline Sales date & Day, month, year when the transaction took place \\
\hline Auction house name & Name of auction house that held the sale \\
\hline Collection sale & $\begin{array}{l}\text { Dummy indicating if artwork was part of a sale where an entire collection } \\
\text { was sold (mostly the case for posthumous sales) }\end{array}$ \\
\hline Seller name & First and last name of the seller \\
\hline Buyer name & First and last name of the buyer \\
\hline
\end{tabular}




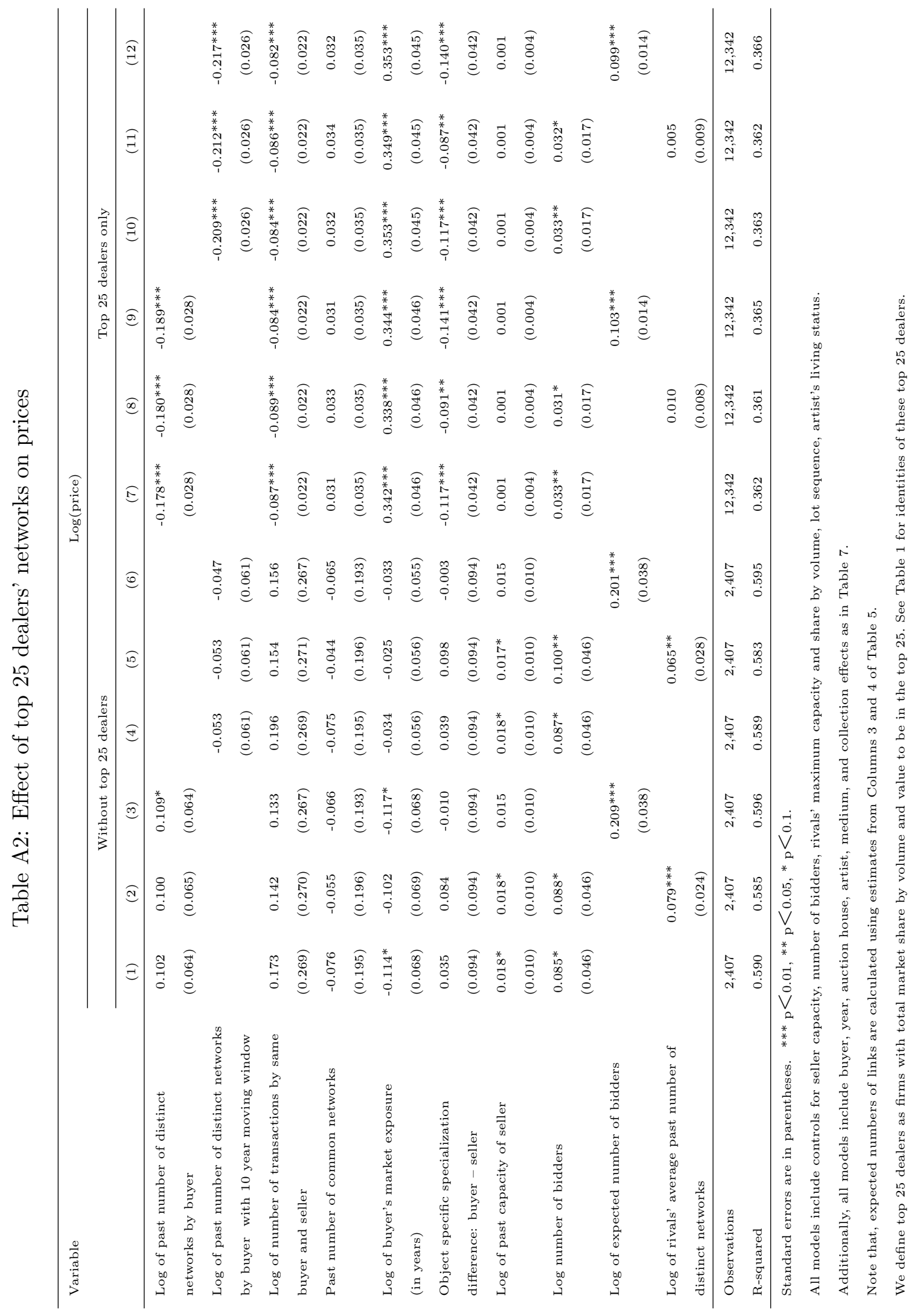


Table A3: Probability of exit without top 25 dealers

\begin{tabular}{|c|c|c|c|c|}
\hline \multirow[t]{2}{*}{ Variable } & \multicolumn{4}{|c|}{ Without top 25 dealers } \\
\hline & $(5)$ & (6) & (7) & $(8)$ \\
\hline \multirow[t]{2}{*}{ Log of past number of direct buyer links } & $-0.019 * * *$ & & $-0.024^{* * *}$ & \\
\hline & $(0.006)$ & & $(0.006)$ & \\
\hline Log of past number of direct buyer links & & $-0.012^{* *}$ & & $-0.017^{* *}$ \\
\hline with 10 year moving window & & $(0.006)$ & & $(0.006)$ \\
\hline \multirow[t]{2}{*}{ Log of buyer's market exposure (in years) } & $-0.010 * * *$ & $-0.007^{* * *}$ & $-0.012^{* * *}$ & $-0.009^{* * *}$ \\
\hline & $(0.002)$ & $(0.002)$ & $(0.002)$ & $(0.001)$ \\
\hline Log of past number of direct buyer links & $0.006^{* * *}$ & & $0.007 * * *$ & \\
\hline$\times \log$ of buyer's market exposure (in years) & $(0.002)$ & & $(0.001)$ & \\
\hline Log of past number of direct buyer links with 10 year moving window & & $0.004^{* * *}$ & & $0.006^{* * *}$ \\
\hline$\times$ Log of buyer's market exposure (in years) & & $(0.002)$ & & $(0.002)$ \\
\hline Buyer's average share (by volume) & -0.216 & $-0.317^{* *}$ & & \\
\hline for the past three years & $(0.146)$ & $(0.142)$ & & \\
\hline Buyer's average share (by value) & & & -0.022 & -0.062 \\
\hline for the past three years & & & $(0.030)$ & $(0.055)$ \\
\hline \multirow[t]{2}{*}{ Log of average number of rivals' networks } & $0.009 * * *$ & $0.008^{* * *}$ & $0.011^{* * *}$ & $0.010^{* * *}$ \\
\hline & $(0.003)$ & $(0.003)$ & $(0.003)$ & $(0.003)$ \\
\hline \multirow[t]{2}{*}{ Number of rival dealers } & -0.003 & -0.003 & -0.002 & -0.002 \\
\hline & $(0.005)$ & $(0.005)$ & $(0.006)$ & $(0.006)$ \\
\hline Genre specialization & Yes & Yes & Yes & Yes \\
\hline Observations & 3,754 & 3,754 & 3,754 & 3,754 \\
\hline Log pseudolikelihood & -325.800 & -335.000 & -326.900 & -337.300 \\
\hline
\end{tabular}




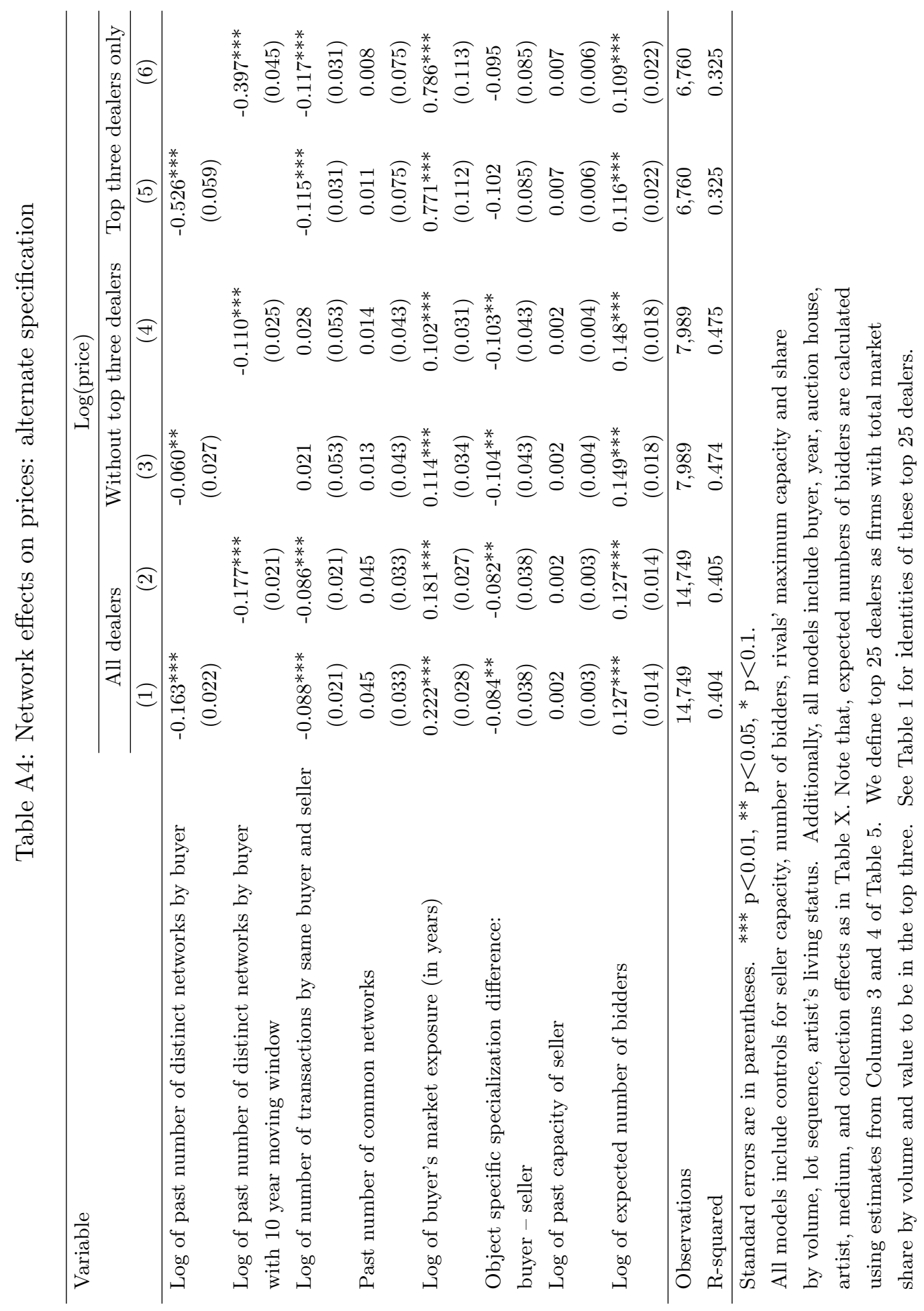


Table A5: Effect of top 25 dealers' networks on prices: alternate specification

\begin{tabular}{lcccc}
\hline Variable & \multicolumn{3}{c}{ Log(price) } \\
\cline { 2 - 5 } & Without top 25 dealers & Top 25 dealers only \\
\cline { 2 - 5 } & $(1)$ & $(2)$ & $(3)$ & $(4)$ \\
\hline Log of past number of distinct networks by buyer & $0.108^{*}$ & & $-0.186^{* * *}$ \\
& $(0.064)$ & & $(0.028)$ \\
Log of past number of distinct networks by buyer & & -0.047 & $-0.208^{* * *}$ \\
with 10 year moving window & & $(0.061)$ & $(0.026)$ \\
Log of number of transactions by same buyer and seller & 0.133 & 0.151 & $-0.082^{* * *}$ & $-0.080^{* * *}$ \\
& $(0.267)$ & $(0.268)$ & $(0.022)$ & $(0.022)$ \\
Past number of common networks & -0.065 & -0.057 & 0.029 & 0.030 \\
Log of buyer's market exposure (in years) & $(0.194)$ & $(0.194)$ & $(0.035)$ & $(0.035)$ \\
Object specific specialization difference: & $-0.117^{*}$ & -0.037 & $0.341^{* * *}$ & $0.345^{* * *}$ \\
buyer - seller & $(0.068)$ & $(0.055)$ & $(0.046)$ & $(0.045)$ \\
Log of past capacity of seller & -0.007 & 0.001 & $-0.128^{* * *}$ & $-0.127^{* * *}$ \\
& $(0.094)$ & $(0.094)$ & $(0.043)$ & $(0.043)$ \\
Log of expected number of bidders & 0.016 & 0.015 & 0.000 & 0.000 \\
& $(0.010)$ & $(0.010)$ & $(0.004)$ & $(0.004)$ \\
Observations & $0.202^{* * *}$ & $0.204^{* * *}$ & $0.113^{* * *}$ & $0.111^{* * *}$ \\
\hline Stanquared & $(0.041)$ & $(0.040)$ & $(0.015)$ & $(0.015)$ \\
\hline
\end{tabular}

Standard errors are in parentheses. $* * * \mathrm{p}<0.01,{ }^{* *} \mathrm{p}<0.05, * \mathrm{p}<0.1$.

All models include controls for seller capacity, number of bidders, rivals' maximum capacity and share by volume, lot sequence, artist's living status. Additionally, all models include buyer, year, auction house, artist, medium, and collection effects as in Table 7. Note that, expected numbers of bidders are calculated using estimates from Columns 3 and 4 of Table 5. We define top 25 dealers as firms with total market share by volume and value to be in the top three. See Table 1 for identities of these top 25 dealers. 